\title{
INVESTIMENTO EXTERNO DIRETO NA AMÉRICA LATINA: O PAPEL DOS ACORDOS DE INVESTIMENTO
}

\author{
Ignácio Tavares de Araújo Júnior ${ }^{1}$
}

\begin{abstract}
SINOPSE
Com exceção do Brasil, os países da América Latina aumentaram consideravelmente suas redes de tratados bilaterais de investimento (TBIs) durante os anos 1990, na busca de ampliar o ingresso de investimento externo direto (IED). Apesar da teoria sobre o tema prever uma relação positiva entre o ingresso de IED e a celebração desses acordos, a literatura empírica não é conclusiva sobre que impactos os TBls exercem sobre o IED, tornando questionáveis os efeitos que esses acordos geraram nas decisões de investimento para a região. Este artigo contribui para a literatura sobre o tema ao analisar como esses acordos têm contribuído para o volume de IED greenfield nos países da América Latina. Um modelo gravitacional foi estimado com essa finalidade, e os resultados indicam que, para os países da América Latina, os TBIs não têm efeito estatisticamente significativo sobre o IED. Os tamanhos das economias, o crescimento econômico, o grau de abertura comercial e a similaridade do retorno do capital têm explicado por que esse tipo de IED tem sido direcionado para os países da região. Evidenciou-se ainda que países com melhor qualidade regulatória atraem mais IED. Países que ratificaram os TBls mas responderam por alguma reclamação em tribunal de arbitragem têm seus fluxos de investimento reduzidos. Por fim, levando em conta os efeitos fixos setoriais, a estimação do modelo gravitacional sugeriu que os TBIs não têm efeito positivo em investimentos nos setores industrial, de serviços e os relacionados à extração de recursos naturais.
\end{abstract}

Palavras-chave: tratados de investimento; investimento externo direto; modelo gravitacional; América Latina.

\begin{abstract}
Except for Brazil, Latin American countries considerably expanded their bilateral investment treaties (BITs) networks during the 1990s, in an attempt to increase FDI inflows. Although the theory on the subject predicts a positive relationship between the inflow of FDI and the conclusion of these agreements, the empirical literature is not conclusive about what impacts TBIs have on FDI, making uncertain the effects that these agreements have had on investment decisions in the region. This article contributes to the literature by analyzing the extent to which these agreements have contributed to the volume of greenfield FDI in Latin American countries. A gravitational model has been estimated for this purpose and the results indicate that for Latin American countries TBIs have no statistically significant effect on FDI. The size of economies, economic growth, trade openness, the similarity in return on capital has explained why this type of FDI has been directed to countries in the region. It was also evident that countries with better regulatory quality attract more FDI. Countries that have ratified most TBI but have responded to some claims in arbitration courts have their investment flows reduced. Finally, taking sectoral fixed effects into account, the estimation of the gravitational model suggested that TBIs have no positive effect on investments in the industrial, services and natural resource extraction sectors.
\end{abstract}

Keywords: investment treaties; foreign direct investment; gravity model; Latin America.

JEL: F21; F23; N4.

Artigo recebido em 18/12/2020 e aprovado em 1/2/2021.

DOI: http://dx.doi.org/10.38116/bepi29art8

\footnotetext{
1. Professor do Departamento de Economia da Universidade Federal da Paraíba (DE-UFPB); pesquisador do Laboratório de Economia e Modelagem Aplicada (LEMA) da UFPB; doutor em economia pelo programa de pós-graduação em economia da Universidade Federal de Pernambuco (Pimes-UFPE). E-mail: <ignacio.tavares@gmail.com>.
} 


\section{INTRODUÇÃO}

Um tratado bilateral de investimento (TBI) é um acordo entre dois países que estabelece o tratamento dispensado ao investimento realizado num dos países por uma empresa do outro país. Eles foram concebidos inicialmente para garantir segurança jurídica adicional para os investimentos realizados por empresas dos países desenvolvidos nos países em desenvolvimento (UNCTAD, 2000). De acordo com Hallward-Driemeier (2003), Neumayer e Spess (2005), Guzman (2009) e Kohler e Stähler (2016), a adoção de acordos bilaterais de investimentos é resposta para problemas de hold-up (comportamento oportunista) ou de inconsistência dinâmica nos países em desenvolvimento tentando atrair investimentos externos diretos (IEDs), principalmente quando este envolve custos irrecuperáveis.

Os TBIs dariam maior segurança ao IED, prevendo vultosas indenizaçóes aos investidores, caso houvesse expropriaçôes diretas e indiretas por parte do país receptor do investimento. De acordo com Kerner (2009), para o país hospedeiro do IED, a assinatura do TBI pode atrair investimentos de outros países com os quais náo possui acordo, pois o tratado dificulta a aplicação de leis dos países receptores do investimento que poderiam ser interpretadas como expropriação. Nessa direção, Neumayer e Spess (2005) argumentam que a assinatura de TBIs envia um sinal para potenciais investidores de que o país em desenvolvimento é geralmente sério sobre a proteção do investimento estrangeiro, demonstrando assim seu compromisso com os direitos de propriedade de investidores externos. Para os países em desenvolvimento, muitos deles apresentando instituiçóes frágeis ou sem a reputação dos países já desenvolvidos, os TBIs eram vistos como substitutos para as instituiçóes locais.

Diante das evidências de que o sólido contexto institucional é importante para atrair IED (Bénassy-Quéré, Coupet e Mayer, 2007), os países em desenvolvimento buscaram celebrar TBIs ao redor do mundo durante os anos 1990, na expectativa de se tornarem mais atrativos para o IED e devido aos potenciais benefícios desse tipo de investimento em termos de geração de empregos, assimilação de novas tecnologias e crescimento econômico.

Seguindo essa tendência mundial, na América Latina, à exceção do Brasil, ${ }^{2}$ todos os países ratificaram acordos de investimento durante os anos 1990 e início dos anos 2000.

Os países da região possuem um histórico de instabilidade em suas instituiçóes, e a ratificação de TBIs pode ter sido uma opção para oferecer um ambiente favorável ao desenvolvimento de projetos de investimento de empresas estrangeiras. O propósito deste artigo é justamente investigar como a celebração desses tratados de investimento influenciou o ingresso de IED na América Latina entre 2003 e 2018. A estratégia empírica se baseia na estimação de um modelo gravitacional com dados em painel para o IED na região. Os dados utilizados se referem apenas ao greenfield investment originado de 94 países e destinado a 39 setores de atividade econômica distintos de 23 países da América Latina.

A despeito dos argumentos teóricos sugerindo que os acordos de investimento teriam efeitos positivos no ingresso de IED, ${ }^{3}$ a literatura empírica sobre o tema indica que os TBIs não necessariamente impactam positivamente sobre o IED como destaca Hallward-Driemeier (2003). Concomitantemente às incertezas sobre os efeitos positivos do TBI sobre o IED, esses tipos de acordo têm sofrido severas críticas em razão da interferência na soberania reguladora doméstica que os países em desenvolvimento

2. 0 Brasil ratificou seu primeiro acordo de investimento em 2017, apesar de já ter assinado vários deles com países como França, Alemanha, Itália e Dinamarca nos anos 1990.

3. A literatura teórica sobre a relação entre TBIs e IED é discutida no artigo Tratados bilaterais de investimento: conceitos, potenciais impactos e tendências futuras, publicado neste volume. 
aceitam ao assinar TBIs e, por seguinte, se submeterem às cláusulas dos mecanismos de solução de controvérsias do acordo (Neumayer e Spess, 2005; Elkins, Guzman e Simmons, 2006). Além dessa submissão, os mecanismos de solução de controvérsias podem gerar riscos jurídicos e financeiros adicionais sem necessariamente elevar o ingresso de IED. Os riscos de incorrer nesses custos ocupam lugar central nas críticas aos TBIs, motivando inclusive o encerramento de vários acordos. ${ }^{4}$

Portanto, diante das incertezas sobre a responsividade do IED à assinatura de TBIs, além dos potenciais custos envolvidos, é importante confirmar se os impactos esperados sobre o IED ocorreram na regiáo. Além de investigar se os acordos de investimento tiveram influência sobre o IED, este estudo irá apontar como o ambiente regulatório de cada país impacta na atração de investimento externo. No período analisado, alguns países da América Latina, como Equador e Argentina, tiveram que responder a diversas queixas de investidores em tribunais internacionais por terem supostamente violado termos dos seus acordos de investimento. Será verificado se essas reclamaçôes de investidores tiveram alguma influência sobre o IED.

Além desta introdução, o artigo possui mais cinco seções. A seção 2 apresenta uma revisão da literatura empírica que investiga como os TBIs podem influenciar o ingresso de IED. Na seção 3 será descrita a estratégia empírica do estudo. Em seguida, na seção 4, será apresentado um panorama sobre os TBIs na região e os investimentos realizados na América Latina. Na seção 5 serão reportados e discutidos os resultados da estimação do modelo econométrico. Por fim, na seção 6, algumas conclusóes serão apresentadas.

\section{RELAÇÃO ENTRE TBIS E IED: O QUE DIZEM OS ESTUDOS EMPÍRICOS}

Além de trazer as evidências sobre a relação entre TBIs e IED, nesta seção serão discutidos estudos empíricos sobre como os mecanismos de soluçáo de controvérsias dos TBIs afetam essa relação. A relação entre a assinatura e/ou ratificação de TBIs e o ingresso de IED tem sido estudada sob diferentes perspectivas. Alguns estudos analisam o impacto sob o fluxo global de investimentos externos, diferenciando apenas se o país possui ou não acordos de investimento. Outros trabalhos diferenciam os investimentos entre originados dos países com os quais o país tem acordo e investimentos globais e também originados de países desenvolvidos e em desenvolvimento. Por fim, serão apresentadas as evidências encontradas sobre como os tratados de investimento podem estar influenciando o investimento externo conforme o setor econômico.

\subsection{Impacto do TBI sobre o IED}

Nesta subseção são apresentados estudos que tentaram evidenciar a relação entre TBI e o ingresso de IED. A maioria dos estudos é do tipo cross-country, visando, a partir de dados longitudinais de diversos países, identificar a relação causal em tela. Também foram incluídos nesta revisão estudos específicos para alguns países.

Hallward-Driemeier (2003) tem foco nos fluxos de investimentos de vinte países da Organização para a Cooperação e Desenvolvimento Econômico (OCDE) para 31 países em desenvolvimento, cobrindo o período de 1980 a 2000 e $85 \%$ dos investimentos originados nos países da OCDE

4. Segundo UNCTAD (2018), o ano de 2017 foi concluído com o menor número de novos acordos internacionais de investimento desde 1983, e pela primeira vez o número de tratados com prazo encerrado superou o número de novas conclusões de acordos de investimento. 
direcionados para os países em desenvolvimento. Mesmo considerando a presença de endogeneidade na análise, a referida autora não encontrou evidências de que o TBI tenha impacto positivo no IED. Em alguns casos, o TBI apresenta efeito negativo. A autora estudou ainda como os TBIs e a qualidade das instituiçóes locais estão relacionados. Os resultados encontrados sugerem que os TBIs têm efeito positivo quando interagem com variáveis representando as instituições locais. Ou seja, os TBIs são efetivos em atrair IED em cenários de elevada qualidade institucional e onde as instituiçóes já estejam sendo fortalecidas. Isso enfraquece a racionalidade central de alguns países menos desenvolvidos que participam desses acordos na esperança de contornar a necessidade de fortalecer os direitos de propriedade e a qualidade das instituiçóes.

Rose-Ackerman e Tobin (2005) investigaram se o ingresso de investimento estrangeiro está associado positivamente com os TBIs e se o efeito do TBI é mais evidente em países com maiores riscos para o investimento. A análise cobriu o período entre 1984 e 2000, utilizando dados de países de diversos níveis de desenvolvimento. Os autores concluem que os TBIs, por si só, parecem ter pouco impacto sobre o IED, sugerindo ainda que um país deve ter algum nível mínimo de estabilidade política antes que os TBIs tenham um efeito positivo sobre sua capacidade de atrair IED.

Egger e Pfaffermayr (2004) avaliam como acordos bilaterais de investimento podem impactar no estoque de IED. Os autores utilizaram uma amostra de 55 países entre 1959 e 1999, totalizando 4.291 observaçóes, sendo 2.789 delas refletindo relaçóes entre países membros da OCDE e 1.446 observaçóes com informaçóes sobre as relaçôes entre participantes e não participantes da OCDE. Os resultados alcançados indicam que firmar um TBI tem impacto positivo de $30 \%$ sobre o estoque de IED. Os autores ressaltam que ratificar o acordo tem impacto maior do que simplesmente assiná-lo. As vantagens de simplesmente assinar um TBI e não o ratificar seriam irrelevantes. As evidências de impacto positivo dos TBIs sobre os estoques de IED são robustas à inclusão de variáveis de infraestrutura, tributação e efeitos de participação em bloco comercial e ao uso de medidas alternativas de diferenças de dotação de fatores.

De acordo com Neumayer e Spess (2005), países em desenvolvimento que assinam mais TBIs recebem mais fluxos de IED. O efeito é robusto para vários tamanhos de amostra, especificaçóes de modelos e os fluxos de IED que são normalizados pelo fluxo total de IED para os países em desenvolvimento. $\mathrm{O}$ aumento de um desvio-padrão na variável TBI em um país em desenvolvimento aumenta o ingresso de IED entre $43,7 \%$ e $93,2 \%$ e, consequentemente, tal país aumentaria sua participaçáo no fluxo de IED em relação à entrada total nos países em desenvolvimento entre $42,0 \%$ e 104,1\%. Todavia, segundo os achados do trabalho, não há fortes evidências de que os TBIs funcionam como substitutos da qualidade institucional.

Para entender a importância dos TBIs na atração de IED na América Latina, Gallagher e Birch (2006) estimaram modelos de regressóes com efeitos fixos com dados de 24 países da regiáo entre 1980 e 2003, incluindo dados sobre tamanho de mercado, estabilidade macroeconômica e dotação de fatores. $\mathrm{O}$ estudo confirma que o tamanho do mercado, a abertura comercial e a estabilidade macroeconômica são os mais importantes determinantes do IED na região. Os autores evidenciaram que o número de TBIs que o país assinou tem impacto positivo sobre o IED. Todavia, o fato de o país ter um acordo de investimento com os Estados Unidos parece não atrair investimentos desse país. Para os países da América do Sul, apenas o tamanho do mercado é relevante para atrair os investimentos de empresas americanas. 
As evidências encontradas por Tobin e Rose-Ackerman (2011), a partir de dados cobrindo 97 países no período de 1984 a 2007, sugerem que o impacto positivo dos TBIs sobre o IED está condicionado a aspectos do ambiente político e econômico. Haveria pouco impacto direto dos TBIs sobre os fluxos de IED. Por exemplo, os resultados encontrados pelos autores indicam que à medida que o nível de risco diminui e a capacidade econômica de um país aumenta, o impacto dos TBIs sobre o IED torna-se mais forte. Ao mesmo tempo, à medida que mais países do mundo entram em TBIs, reduz-se o impacto positivo dos TBIs sobre o IED. Em todas as especificaçóes, o risco político diminuído tem um impacto positivo nos fluxos de IED. No entanto, em vez de agir como um substituto para o risco político, os resultados confirmam a hipótese de que os TBIs agem para aumentar o efeito positivo sobre o IED do país com baixo risco. Especificamente, para cada ponto que um país melhora na escala de risco político considerada no artigo, o impacto de um TBI adicional resulta num aumento de $1,1 \%$ nos fluxos de IED.

Pradhan (2011), analisando as decisões de investimentos de empresas da Índia e da China, mostrou que as empresas indianas dão preferência para países com os quais a Índia tem acordos de investimentos. Não foram encontradas evidências de que as empresas chinesas guiem suas decisóes de investimento com base na existência de acordos de investimentos. O estudo de Bae e Keum (2013) mostra que os TBIs aparentam ter um pequeno efeito sobre investimentos da Coreia do Sul no exterior, mas náo têm efeito sobre influxo de investimentos no país. Os autores evidenciaram que acordos comerciais estimulam tanto o ingresso como a realização de investimentos estrangeiros na Coreia do Sul.

Egger e Merlo (2012) estudaram os efeitos dos TBIs na atuação de multinacionais alemãs no exterior. Os autores realizaram o estudo a partir de microdados de empresas. Isso permitiu levar em conta aspectos dos investimentos de multinacionais no exterior, o que os estudos feitos com dados agregados não conseguem. Segundo a análise, a ratificação dos TBIs eleva o número de empresas no país anfitrião médio em 26 unidades. Ademais, a celebração de um TBI tem o potencial de reduzir os custos fixos de investimento no país anfitriáo típico em cerca de $€ 3,7$ milhôes. O IED gerado pela assinatura e ratificação de um TBI é de cerca de $€ 5$ milhóes por empresa e, portanto, $€ 130$ milhôes por país de acolhimento, em média.

A partir de uma amostra de 125 países em desenvolvimento (excluindo a China) e países da OCDE, cobrindo o período entre 1971 e 2006, Lee e Jhonston (2016) estudaram se os TBIs de países em desenvolvimento assinados com países mais ricos têm efeito positivo não apenas no IED do país fonte signatário mas também no IED vindo de outros países. O trabalho revelou que os TBIs ajudam a atrair IED somente quando são assinados com países mais poderosos e ricos. Ademais, os TBIs atraem investimentos de outros países que não os signatários do tratado. Segundo os autores, a teoria anteriormente apresentada é corroborada, uma vez que as evidências encontradas sugerem que a assinatura de TBIs aumenta a reputação do país signatário porque os investidores estrangeiros atualizam suas crenças na proteção legal ao investimento externo em um país em desenvolvimento depois que ele participa de um TBI com um país influente.

Falvey e Foster-Mcgregor (2017) investigaram se os efeitos dos TBIs sobre o IED são não lineares. Os TBIs são assinados entre pares de países altamente heterogêneos, com diferenças importantes em termos de tamanho da economia e nível de desenvolvimento - produto interno bruto (PIB) per capita -, e o interesse do estudo foi saber se algumas dessas diferenças sistemáticas ajudam a explicar os resultados mistos dos efeitos dos TBIs sobre os fluxos de IED. Na análise realizada foi utilizada uma 
amostra de 22 países da OCDE como países de origem do IED e uma amostra de 101 economias hospedeiras menos desenvolvidas. Os autores encontraram evidências de que os impactos do TBI sobre o IED são mais fortes à medida que aumentam as diferenças entre PIB e PIB per capita entre os países fonte e destino do IED.

\subsection{Mecanismos de solução de controvérsias e seus efeitos no IED}

Em teoria, a segurança jurídica para o investidor externo propiciada pelos mecanismos de soluçáo de controvérsias ajuda a explicar parte do impacto do TBI sobre o IED. A literatura relata diferentes formatos para esses mecanismos jurídicos, alguns sendo mais rigorosos do que outros em favor do investidor em eventuais disputas investidor-Estado. Apesar da evidente importância de se conhecer como esse canal de transmissão do efeito do TBI sobre o IED opera, poucos trabalhos se debruçaram sobre essa especificidade. A seguir, serão apresentados os trabalhos relevantes que foram publicados sobre esse tema.

Em Berger et al. (2011) tem-se a primeira tentativa de observar como os diferentes mecanismos de solução de controvérsias presentes nos TBIs podem impactar o IED. Em alguns TBIs esses mecanismos são praticamente ausentes e em outros apresentam cláusulas mais estritas, que regulamentam os compromissos mútuos assumidos entre as partes. Em seu estudo empírico, os autores utilizaram médias de três anos de fluxos de IED a partir de quatorze países fonte para 83 países em desenvolvimento receptores durante o período 1978-2004. Os autores incluíram variáveis dummy indicando se o TBI possui mecanismo de solução de disputas entre investidor e Estado (Investor-State Dispute Settlement - ISDS) e cláusulas de pré-consentimento.

Inicialmente constatou-se que os países com TBIs aprestam maiores fluxos de IED, e esse efeito positivo do TBI sobre o IED é atribuído à presença de ISDS. A presença de cláusulas mais rígidas no TBI, porém, não apresentou impacto estatisticamente significativo no IED. Os autores detectaram que esse resultado é sensível à composição da amostra de países. Quando se excluem os países do Leste Europeu, o TBI e a presença de ISDS não influenciam mais o IED. Isso ocorre devido à ausência de reputação em relaçáo ao tratamento dado ao IED após a mudança de regime econômico desses países. A simples ratificação de um TBI já estimularia o ingresso de investimentos externos nos países daquela regiáo.

Por fim, o trabalho sugere que os TBIs podem ser mais relevantes para empresas de pequeno porte que desempenharam um papel importante para os fluxos de IED para os países do Leste Europeu, em comparação com as grandes multinacionais que muitas vezes celebram contratos diretos e personalizados com os governos dos países anfitrióes.

Em artigo recente, Frenkel e Walter (2019) investigaram como as diferentes provisóes de mecanismos de solução de controvérsias podem afetar os impactos dos TBIs no IED. Os autores inovaram ao criar um índice para cada TBI baseado no tipo de instrumento de soluçâo de disputa do acordo.

Em seu modelo econométrico, o IED seria determinado pela presença dos TBIs e pelo índice criado, além dos controles tradicionais. Os resultados encontrados mostram que tanto o ingresso como o estoque de IED não são influenciados pela quantidade de TBIs. O índice criado tem efeito positivo e estatisticamente significante, sugerindo que países com TBIs com especificaçôes mais rigorosas nos instrumentos de soluçáo de controvérsias têm maiores ingressos de IED. 
Quando os autores estimam seu modelo apenas para os países em desenvolvimento, encontra-se um efeito positivo tanto do número de TBIs como no índice que mede o rigor dos instrumentos de solução de controvérsias. Utilizando o método dos momentos generalizados para corrigir a provável endogeneidade no modelo, os autores encontraram resultado similar para a amostra de países em desenvolvimento. No estudo ainda foi constatado um aumento do impacto da força do acordo, mensurado pelo rigor de suas previsóes legais, sobre o IED à medida que o número de TBIs aumenta. O rigor do TBI tem impacto expressivo nos fluxos bilaterais entre as partes, principalmente quando uma das partes é um país em desenvolvimento.

Allee e Peinhardt (2010) testaram se o efeito positivo dos TBIs sobre o IED é condicionado ao comportamento do país receptor do investimento ao longo do acordo. Para esses autores, quando são acionados em fóruns internacionais de arbitragem, tal como o Centro Internacional para Arbitragem de Disputas sobre Investimentos (International Centre for Settlement of Investment Disputes ICSID), os países receptores perdem a credibilidade conquistada por meio da assinatura do TBI, desencorajando novos investidores a direcionar seus recursos para o país.

Os autores utilizaram dados de uma grande amostra de países, cobrindo o período entre 1984 e 2007. As evidências encontradas dão suporte para a relação positiva entre o número de TBIs e o ingresso de IED. No entanto, os governos que foram acionados no ICSID por violar os compromissos assumidos experimentam quedas elevadas no investimento estrangeiro. Governos que eventualmente perdem disputas do ICSID experimentam perdas ainda maiores no ingresso de IED. Ou seja, o ganho efetivo de credibilidade com o TBI é alcançado seguindo-se o compromisso assumido no acordo. $\mathrm{O}$ trabalho ainda indica que governos que são respondentes únicos no ICSID conseguem recuperar os patamares anteriores de IED entre três e cinco anos. No longo prazo, portanto, os benefícios de assinar um TBI superariam as perdas sofridas.

Num trabalho similar ao citado anteriormente, Aisbett, Busse e Nunnenkamp (2018) estudaram como um país em desenvolvimento membro do TBI ser acionado em tribunal de arbitragem impacta o ingresso de IED nesse país. Uma importante hipótese testada nesse trabalho foi a de que os TBIs têm um papel dissuasivo nos países em desenvolvimento, em razão da ameaça de uma disputa entre investidor e Estado e nos consequentes custos envolvidos nessa disputa.

As evidências encontradas pelos autores indicam que a participação no TBI estimula os fluxos bilaterais de IED, mas apenas enquanto o país em desenvolvimento anfitrião não tiver uma queixa num tribunal de arbitragem. Em outras palavras, se o país receptor do investimento for acionado por algum país em razão de um suposto não cumprimento dos termos do TBI, outros países inferirão que a ameaça de uma disputa de TBI não é um impedimento suficientemente forte para dissuadir aquele país em particular de descumprir os termos do TBI. Ademais, esse impacto negativo das reclamaçôes sobre os fluxos de IED para os países em desenvolvimento aumenta com o número de reclamaçôes apresentadas em um determinado ano contra o país anfitrião. Esse resultado é robusto em diferentes composiçóes de amostra e controle para endogeneidade.

\subsection{TBI e IED por setores}

Parte da necessidade de ratificar um TBI se deve ao problema de inconsistência dinâmica provocado pela presença de custos irrecuperáveis nos investimentos. Colen, Persyn e Guariso (2016) foi o único trabalho encontrado que estudou se os investimentos que possuem custos irrecuperáveis estão 
positivamente correlacionados a existência de TBIs. O artigo representa a primeira tentativa de estudar empiricamente o efeito heterogêneo que os TBIs podem ter em diferentes tipos de investimentos. Nele, os autores argumentam que os TBIs seriam mais eficazes nos setores da economia caracterizados por grandes custos irrecuperáveis.

O estudo foi conduzido a partir de uma amostra de dados de IED setoriais desagregados para treze países em transição da Europa Central e Oriental e da antiga União Soviética. As evidências indicam que os TBIs têm impacto positivo e náo desprezível sobre o IED. O fato de um país fazer parte de algum TBI faz o estoque de IED aumentar cerca de $1 \%$ a $2 \%$.

Os TBIs parecem ser mais bem sucedidos em atrair investimentos estrangeiros em serviços de utilidade pública, que possuem um elevado grau de irreversibilidade. Houve efeitos positivos, mas em menor magnitude, nos setores bancário e de construção civil, enquanto nenhum efeito do TBI foi encontrado para investimentos nos setores industrial e de serviços. Essas diferenças de resultados seriam explicadas pelas diferenças no grau de irreversibilidade dos investimentos entre os setores. Em outras palavras, os TBIs parecem ter relação positiva com investimentos com elevado grau de irreversibilidade.

\section{ESTRATÉGIA EMPÍRICA}

\subsection{Modelo econométrico}

Para alcançar os objetivos propostos neste estudo, será estimado um modelo gravitacional para IED na América Latina. Assim, para explicar o comércio entre países, o modelo gravitacional para IED pressupóe que o fluxo de IED do país $i$ para o país $j$ depende de variáveis que tornam mais provável a existência desse fluxo, tal como os tamanhos das duas economias e a distância entre elas. As teorias sobre IED sugerem ainda que ele estaria relacionado com outras variáveis dos países de destino, tais como o contexto institucional (Daude e Stein, 2007), a dotação e custos dos fatores de produção, as economias de aglomeração e incentivos oferecidos pelo governo local às empresas estrangeiras (Faeth, 2009). Dessa forma, o modelo empírico para os determinantes IED a ser estimado neste estudo segue o formato da equação (1).

$$
\begin{aligned}
I E D_{i j t}= & \beta_{0}+\beta_{1}\left(P I B_{i t} \cdot P I B_{j t}\right)+\beta_{2} G R W_{j t}+ \\
& \delta \cdot D T B I_{i j t}+\sum_{k=3}^{n} \beta_{k} X_{k j t}+\alpha_{i}+\gamma_{j}+\vartheta_{t}+\omega_{i j}+u_{i j t} .
\end{aligned}
$$

Em que IED é uma variável representando o valor de IED do país $i$ (país de origem do IED) para o país $j$ (destino do IED) na América Latina. Assim como em Mistura e Roulet (2019), Head e Ries (2008) e Bénassy-Quéré, Coupet e Mayer (2007), o IED na equação 1 será representado pelo estoque nominal de IED que o país $i$ investiu no país $j$. O ingresso de IED representado pelo estoque é menos volátil do que o fluxo anual, principalmente para países pequenos. Ademais, como destaca Bénassy-Quéré, Coupet e Mayer (2007), o estoque de IED representa melhor a decisão de investimento do que o fluxo anual. $\mathrm{O}$ efeito do TBI sobre o IED será estimado incluindo uma variável dummy $D T B I_{i j t}$ que é igual a 1 se o país $i$ tem um TBI vigente com o país $j$ no ano $t$, e zero caso contrário. Os demais regressores tentam levar em conta as variáveis com as quais o IED está relacionado, tais 
como as chamadas variáveis gravitacionais representadas pelos tamanhos das economias de origem e de destino do IED, mensurados pelo PIB real de cada país, e a taxa de crescimento do PIB no país de destino $\left(G R W_{j t}\right)$. No vetor $X$, estão incluídos n regressores do país de destino do IED, que tradicionalmente compóem as equaçóes de investimento, tais como a taxa bilateral de câmbio e o grau de abertura comercial.

Com relação ao efeito da taxa de câmbio sobre o IED, enquanto uma apreciação da moeda do país de origem da empresa reduz o custo do investimento no exterior, o retorno do investimento também diminui na moeda de origem. Consequentemente, a taxa de câmbio tem pouco efeito sobre a decisão de IED. Pode-se argumentar também que a desvalorização da taxa de câmbio do país de destino do IED atrai investimentos externos em razão da consequente redução do custo de capital para a empresa estrangeira, que possui acesso a meios de financiamento de menor custo para investir quando comparado com as empresas do país de destino do IED, o qual enfrenta a desvalorizaçáo cambial (Blonigen, 1997).

Helpman (2006) argumenta que as decisôes de IED e de comércio internacional são tomadas em conjunto. Para uma empresa estrangeira, é preferível produzir em países com restriçóes importantes para fazer comércio do que exportar para esses países. Apesar de haver custos fixos para a introduzir a nova planta, a empresa náo incorreria em elevados custos para realizar comércio com esse país (Helpman, 1984).Esses países seriam mais propensos a receber projetos de integração horizontal.

Já países que apresentam mais facilidade para realizar comércio, seriam mais propensos a receber projetos de integração vertical, que comporiam a rede de fornecedores da multinacional e/ou serviriam de plataforma de exportaçáo de insumos para cadeias produtivas de outras empresas.

Segundo Nicoletti et al. (2003), Fournier (2015) e Mistura e Roulet (2019), variáveis que indiquem similaridade entre os países de origem e destino do IED em aspectos como tamanho e dotação de fatores poderiam representar a maior predisposição do país de receber projetos horizontais ou verticais de IED.

Neste estudo será utilizado o indicador de similaridade do tamanho das economias de destino e origem do IED adotado por Nicoletti et al. (2003), Fournier (2015) e Mistura e Roulet (2019) (ver equação 2). Segundo Nicoletti et al. (2003), a similaridade de tamanho dos países de origem e destino contribui para IED horizontal, pois a similaridade entres as partes favorece a exploração de economias de escala no nível da empresa para projetos horizontais de IED.

$$
S I M_{i j, t}=\ln \left[1-\left(\frac{P I B_{i, t}}{P I B_{i, t}+P I B_{j, t}}\right)^{2}-\left(\frac{P I B_{j, t}}{P I B_{i, t-1}+P I B_{j, t}}\right)^{2}\right]
$$

Indicadores de dissimilaridades de fatores de produção serão calculados conforme as equaçôes (3) e (4), seguindo Nicolleti et al. (2003), Fournier (2015) e Mistura e Roulet (2019).

$\mathrm{Na}$ equação (3), representa-se as diferenças na relação capital trabalho $(K / L)$ entre os países de origem e destino do IED. Na equação 4, mede-se as diferenças nas dotaçôes de capital humano $(\mathrm{CH})$ entre os países de origem e destino do IED. Segundo Yeaple (2003) a abundância de trabalho qualificado é um fator chave para um país receber IED, assim como as diferenças de dotação de fatores entre os países de origem e destino do IED. Uma maior dissimilaridade de fatores de produção 
entre países pode afastar o IED das empresas de elevada produtividade, que são as mais propensas a realizar investimentos externos em projetos de integração horizontal, como destaca Helpman, Melitz e Yeaple (2004). Quando se buscam fatores de produção de menor produtividade para atuar em etapas do processo de produção (integração vertical), a dissimilaridade pode, no entanto, atrair IED (Fournier, 2015).

$$
\begin{aligned}
& F D_{i j, t}=\left|\ln \left(\frac{K_{i, t}}{L_{i, t}}\right)-\ln \left(\frac{K_{j, t}}{L_{j, t}}\right)\right| \\
& C H D_{i j, t}=\left|\ln \left(C H_{i, t}\right)-\ln \left(C H_{j, t}\right)\right|
\end{aligned}
$$

Neste estudo, será considerado que as diferenças entre as taxas internas de retorno dos países de origem e destino podem explicar os fluxos de IED. Essas diferenças seráo representadas pela medida de dissimilaridade entre as taxas internas de retorno do capital entre os países, calculada por meio da equação (5), em que TIR representa a taxa interna de retorno do capital. Essa variável pode ser relevante porque a decisão de investimento envolve a comparação entre a $T I R$ do capital e o seu custo. ${ }^{5} \mathrm{O}$ projeto é economicamente viável se a TIR supera o custo do capital. Dessa forma, investiga-se se as empresas multinacionais preferem investir em países com taxa interna de retorno e custo do capital semelhantes às observadas nos seus países de origem.

$$
T I R D_{i j, t}=\left|\ln \left(T I R_{i, t}\right)-\ln \left(T I R_{j, t}\right)\right|
$$

A dotação de recursos naturais nos países de destino do IED pode explicar a decisão de investir nesse país, e os países da América Latina, como Chile e Brasil, têm forte presença na extração e no comércio de recursos naturais. Em razáo disso, foi incluída no modelo uma variável que representa a extração de recursos naturais.

Na equação (1) foi incluída também uma variável que indica a qualidade regulatória do país de destino do IED. Segundo o Banco Mundial, ${ }^{6}$ a qualidade regulatória captura percepçóes da capacidade do governo de formular e implementar políticas e regulamentos sólidos que permitam e promovam o desenvolvimento do setor privado. Essa variável faz parte do rol de indicadores que representam a qualidade institucional de um país, que tem importante papel na atração de IED. Assim como as evidências empíricas já apontam (Daude e Stein, 2007; Rammal e Zurbruegg, 2006), espera-se que essa variável também seja relevante para explicar o ingresso de IED na América Latina.

Um aspecto relevante a ser explorado neste artigo é a repercussão sobre o IED quando umas das partes do acordo de investimento sofre alguma reclamaçáo de um ou mais investidores por supostamente ter infringido algum termo do acordo. Os estudos de Allee e Peinhardt (2011) e Aisbett, Busse e Nunnenkamp (2018) evidenciaram uma redução no IED quando o país receptor do investimento for acionado por algum investidor em razão de um suposto não cumprimento dos termos do TBI.

5. Segundo destacam Barrell e Pain (1996), o custo do capital é um determinante importante para os fluxos de IED.

6. Ver World Governance Indicators (WGI). Disponível em: <https:// info.worldbank.org/governance/wgi/>. 
Segundo Aisbett, Busse e Nunnenkamp (2018), em razão desse suposto descumprimento dos termos do acordo, outros países inferirão que a ameaça de uma disputa de TBI não é um impedimento suficientemente forte para dissuadir aquele país em particular de não cumprir os termos do TBI. Será incluída na equaçáo (1) uma variável dummy igual a um se o país $j$ possui um TBI ratificado com o país $i$ e ao mesmo tempo o país $j$ recebeu alguma reclamação de alguma empresa do país $i$ num certo ano t. Será avaliado também de que forma esse impacto muda com a quantidade de reclamaçóes recebidas.

Na estimação da equação (1), conforme sugerido por Egger e Pfaffermayr (2003), serão levados em conta efeitos fixos dos países de origem do IED $\left(\alpha_{i}\right)$, dos países de destino $\left(\gamma_{j}\right)$, dos pares de países $\left(\omega_{i j}\right)$ e efeitos fixos de tempo $\left(\vartheta_{t}\right)$. Os efeitos fixos dos países levam em conta a possibilidade de que variáveis omitidas observáveis e não observáveis de cada país e invariantes no tempo poderiam explicar a decisão de realizar o IED. O efeito fixo de tempo captura possíveis mudanças no ciclo econômico que afetou todos os países simultaneamente. Por fim, considerando o efeito fixo dos pares, os resultados da estimativa dos parâmetros da equação (1) não são afetados por fatores fixos no tempo característicos dos pares de países, tais como ter o mesmo idioma, fazer fronteira, distância e estar na mesma área de livre comércio.

Em uma segunda etapa desta análise, a equação (1) será estimada considerando-se a existência de efeitos fixos setoriais para os países de origem e destino do IED. Esses efeitos fixos têm o potencial de capturar aspectos setoriais observáveis e não observáveis invariáveis no tempo para os dois grupos de países, por exemplo, o fato da estrutura econômica do país de origem/destino tornar mais provável realizar/receber investimentos externos em determinado setor. Na sequência da análise, a equação (1) será estimada com variável de interação entre as variáveis dummy setoriais e a dummy indicando se o país tem acordo de investimento com o país de origem. Dessa forma, será explorado se os TBIs e o IED estão correlacionados de maneira distinta conforme o setor de destino do IED.

A estimação do modelo gravitacional, tanto para estudar fluxos comerciais quanto de investimentos, envolve a linearização por meio da aplicação de uma transformação logarítmica, e um problema recorrente nessa estimação é a presença de zeros na variável dependente. No contexto deste artigo, esses zeros ocorrem quando um país não recebe investimentos de outro país. As soluçóes encontradas na literatura, quando explicitadas, recorrem à simples exclusão dos dados com zero ou a substituição do zero por um pequeno valor que permita a aplicação da transformação logarítmica.

Excluir os zeros do modelo gravitacional faz como que o modelo seja estimado apenas entre os países que recebem investimento, gerando um problema de viés de seleção, pois esses países seriam os mais propensos a receber IED (Helpman, Melitz e Yeaple, 2004). Substituir os zeros do modelo por um valor pequeno pode distorcer a distribuição da variável dependente expressa em logaritmo, pois a transformação logarítmica diminui a dispersão dos dados, expandindo os valores mais baixos e reduzindo os mais elevados. Alternativamente, Falvey e McGregor (2017) aplicam sobre dados de IED a transformação inversa do seno hiperbólico, ${ }^{7}$ porém, para valores pequenos de $y$, essa transformação não reproduz a escala logarítmica. Como sugere Bellemare e Wichman (2019), com dados apresentando muitos zeros, é desejável modelar o processo de geração dos dados explicitamente.

Umas das opçôes disponíveis para estimar o modelo gravitacional sem descartar ou manipular as observaçóes com zeros é usar o método Poisson Pseudo Maximum Likelihood (PPML), conforme recomendam Silva e Tenreyro (2006). Os modelos PPML ao mesmo tempo são robustos na presença

7. A transformação inversa do seno hiperbólico é definida como: $\tilde{y}=\ln (y+\sqrt{y+1})$. 
de heterocedasticidade e modelam os zeros observados nos fluxos de IED. ${ }^{8}$ Por esse motivo, essa abordagem econométrica será utilizada neste artigo.

$\mathrm{Na}$ estimação da equação (1), utilizando PPML, os erros-padrões estão agrupados (clusterizados) conforme os pares de países, porque, nesse tipo de análise, pode haver uma alta persistência do nível do estoque de IED dentro de cada par de países ao longo do tempo, conforme sugere Fournier (2015). Por motivos semelhantes, na versão da equação (1) com efeitos fixos setoriais, os erros padrôes serão agrupados por setor e pares de países. No quadro 1 pode-se observar as variáveis independentes e os sinais esperados para os parâmetros estimados.

\section{QUADRO 1}

Relação de variáveis e sinal esperado para o parâmetro a ser estimado

\begin{tabular}{|l|l|}
\hline \multicolumn{1}{|c|}{ Variável independente } & \multicolumn{1}{c|}{ Sinal esperado para o parâmetro estimado } \\
\hline PIB dos países de origem e destino & Positivo \\
\hline Crescimento do PIB do país de destino & Positivo \\
\hline TBI ratificado & Positivo \\
\hline Taxa bilateral de câmbio & Neutro/positivo \\
\hline Grau de abertura comercial & Negativo/positivo \\
\hline Qualidade regulatória & Positivo \\
\hline Similaridade econômica & Positivo/negativo \\
\hline Dotação de fatores & Positivo/negativo \\
\hline Número de reclamações em tribunais internacionais & Negativo \\
\hline
\end{tabular}

Elaboração do autor.

\subsection{Fontes de dados}

A fonte de dados para o IED é o FDIMarkets, uma plataforma de dados privada que disponibiliza os fluxos anuais bilaterais de IED entre diversos países do mundo. O IED que consta nessa base de dados representa os chamados greenfield investments, ou o IED destinado à abertura de novas empresas ou expansão de atividades já existentes. A plataforma FDIMarkets monitora o IED desde 2003 e permite desagregar os dados até o nível de empresa.

Neste estudo, serão utilizados dados agregados por setores de atividade econômica, devido à dificuldade de construir um banco de dados em painel para empresas. O banco de dados disponível para esta análise contém informaçóes sobre IED originados de 94 países, destinados a 39 setores de 24 países da América Latina, entre 2003 e 2019. No anexo deste estudo, apresenta-se a relação dos países de origem e destino e setores. $\mathrm{Na}$ análise setorial dos efeitos dos TBIs sobre o IED, os setores foram agrupados em três grupos: indústria, serviços e exploração de recursos naturais. No anexo, serão apresentados os setores que compóem esses agrupamentos.

As informaçôes sobre os TBIs (Estados-partes dos acordos e anos de ratificação e conclusão) estão disponíveis no site mantido pela Conferência das Naçóes Unidas para Comércio e Desenvolvimento (United Nations Conference on Trade and Development - UNCTAD), que monitora as políticas de investimento ao redor do mundo.?

8. Silva e Tenreyro (2006) destacam que, na presença de heterocedasticidade, os erros também transformados serão correlacionados com as covariadas, resultando em estimadores inconsistentes para os parâmetros do modelo gravitacional, mesmo considerando a presença de efeitos fixos dos países de origem e destino dos investimentos.

9. Disponível em: <https://investmentpolicy.unctad.org/>. 
Com base nesses dados, foi possível construir a variável dummy $D T B I_{i j}$. Foi possível ainda definir que essa variável náo é invariante no tempo, uma vez que ela passa a ser igual a zero a partir do ano em que o TBI é encerrado.

No mesmo site é possível obter informações sobre os processos abertos por investidores para solução de controvérsias no âmbito dos TBIs. A variável dummy indicando se o país recebeu alguma reclamação foi construída a partir dessas informaçóes, assim como o número de reclamaçóes que o país recebeu. Os dados sobre PIB dos países de origem e de destino do IED, taxa de crescimento do PIB, PIB per capita, taxa de câmbio e grau de abertura comercial foram obtidos no World Development Indicators (WDI) do Banco Mundial. Dados sobre estoque de capital, índice de capital humano, número de trabalhadores e taxa interna de retorno foram coletados na Penn-World Table. O indicador de qualidade regulatória foi obtido no Word Governance Indicators (WGI) do Banco Mundial. A taxa de inflação nos países de destino do IED foi obtida no World Economic Outlook do Fundo Monetário Internacional (FMI). Os dados para a variável que representa o estoque de recursos naturais do país de destino do IED foram extraídos do WDI. Essa variável foi construída agregando-se os lucros de petróleo, gás natural, carvão, mineração e extrativismo florestal, em percentual do PIB.

A variável de crescimento econômico utilizada foi uma média móvel da taxa de crescimento real do PIB do país de destino do IED nos últimos cinco anos. As demais variáveis independentes que irão compor a equação (1) foram defasadas em um período para reduzir a possibilidade de endogeneidade na estimação. Após combinar esses dados em uma única base, o período de análise ficou restrito a 2003-2017 devido à inexistência de alguns dados para 2018. A tabela 1 apresenta estatísticas descritivas das variáveis utilizadas na estimação da equação (1).

\section{TABELA 1}

\section{Estatísticas descritivas das variáveis da equação (1)}

\begin{tabular}{|c|c|c|c|c|}
\hline Variável & Média & Desvio-padrão & Mínimo & Máximo \\
\hline Estoque de IED & 193,52 & 981,17 & 0,00 & $40.000,00$ \\
\hline$P I B_{i} \times P I B_{j}$ & 26,77 & 2,14 & 15,88 & 31,68 \\
\hline Taxa de crescimento do PIB & 1,11 & 0,72 & $-2,94$ & 2,35 \\
\hline PIB per capita & 9,35 & 0,44 & 7,37 & 10,37 \\
\hline TBI (dummy) & 0,40 & 0,49 & 0,00 & 1,00 \\
\hline Grau de abertura comercial & 3,67 & 0,52 & 2,44 & 4,79 \\
\hline Taxa de câmbio & 1,80 & 5,19 & $-25,82$ & 8,73 \\
\hline Similaridade econômica & $-1,86$ & 1,29 & $-9,61$ & $-0,69$ \\
\hline Dissimilaridade de capital humano & 0,27 & 0,19 & 0,00 & 1,13 \\
\hline Dissimilaridade de dotação de fatores & 1,16 & 0,59 & 0,00 & 3,78 \\
\hline Dissimilaridade de TIR & 0,66 & 0,43 & 0,00 & 3,19 \\
\hline Recursos naturais & 1,21 & 1,07 & $-2,87$ & 3,45 \\
\hline Qualidade regulatória & 0,11 & 0,62 & $-1,63$ & 1,54 \\
\hline Respondeu por reclamação em tribunal internacional (dummy) & 0,18 & 0,38 & 0,00 & 1,00 \\
\hline
\end{tabular}

Elaboração do autor. 


\section{VISÃO GERAL DOS DADOS}

\subsection{TBls na América Latina}

No gráfico 1 são apresentados dados sobre a evolução do número de acordos de investimentos ratificados na América Latina da década de 1960 até os dias atuais. Assim como no resto do mundo (UNCTAD, 2018), durante os anos 1990 houve um expressivo aumento no número de TBIs ratificados pelos países da América Latina. Em 2019, a região acumulou mais de 400 TBIs ratificados. O gráfico 1 mostra também que, até o início dos anos 1990, os parceiros nesses acordos eram exclusivamente países de renda elevada, ${ }^{10}$ um fato esperado dado o propósito inicial dos TBIs, que era proteger os investimentos dos países desenvolvidos em nações ainda em desenvolvimento. Todavia, a partir de meados da década de 1990, os países da América Latina passaram a ter parceiros de renda média e baixa. Em 2019 cerca de um terço dos acordos são com esses países. Essa tendência ocorreu em concomitância com a adoção de políticas de liberalização do comércio adotadas na região, que, segundo Perea e Stephenson (2018), foram importantes responsáveis pelo aumento de IED originados em países em desenvolvimento. Ao passarem a ser exportadores de capital, mesmo em menor medida que os países desenvolvidos, é possível que os países da América Latina passem a procurar também proteção para os investimentos realizados pelas suas empresas multinacionais por meio de acordos de investimento com países em desenvolvimento.

\section{GRÁFICO 1}

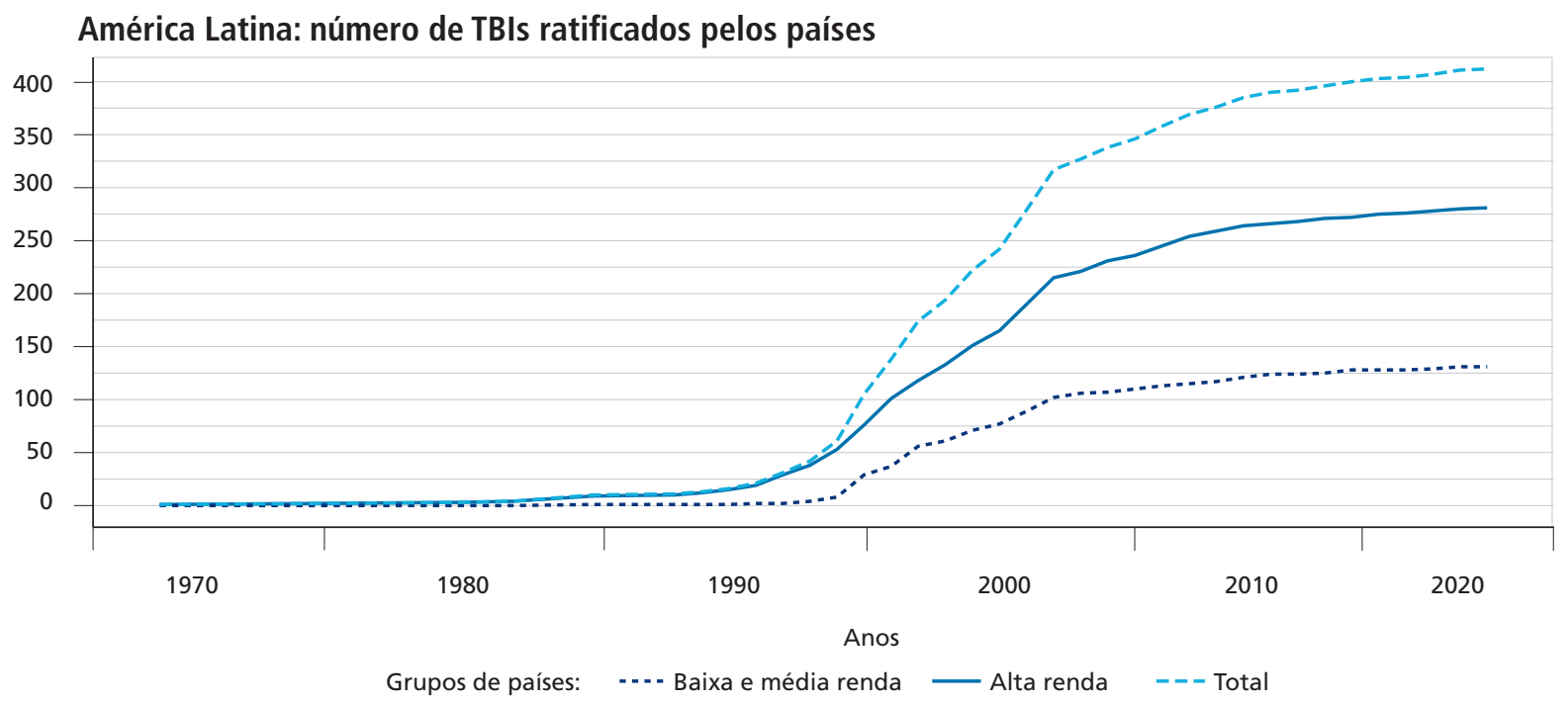

Fonte: UNCTAD.

Elaboração do autor.

Um breve histórico sobre os TBIs ratificados por países da América Latina pode ser observado na tabela 2. O primeiro país a ratificar um TBI foi a Costa Rica, no ano de 1966, tendo como parceiro a Suíça. Poucos anos depois, o Equador ratificou seu primeiro acordo, também com a Suíça. Como já indicado no gráfico 1, a maior parte dos países começou a ratificar seus TBIs a partir da década de 1990. Ao longo das últimas décadas, Argentina e Chile foram os países que ratificaram mais TBIs. 
Os dados ainda indicam que a maior parte dos parceiros nesses acordos é composta por países ricos. A Argentina foge desse padrão, pois possui vários acordos com países de renda média - onze de seus parceiros são países da própria América Latina. Dos 22 acordos que o Brasil assinou desde a década de 1990 , apenas um foi ratificado. ${ }^{11}$

TABELA 2

América Latina: sumário dos TBls ratificados

\begin{tabular}{|c|c|c|c|c|c|}
\hline País & Data do primeiro TBI & Total de TBIs ratificados & TBIs com países de renda elevada & TBls encerrados & Total de reclamações \\
\hline Argentina & 1992 & 54 & 25 & 6 & 61 \\
\hline Barbados & 1993 & 9 & 5 & 0 & 0 \\
\hline Belize & 1982 & 5 & 4 & 0 & 3 \\
\hline Bolívia & 1990 & 22 & 15 & 12 & 17 \\
\hline Brasil & 2017 & 1 & 0 & 0 & 0 \\
\hline Chile & 1994 & 41 & 23 & 5 & 5 \\
\hline Colômbia & 2007 & 9 & 4 & 3 & 13 \\
\hline Costa Rica & 1966 & 16 & 11 & 1 & 10 \\
\hline República Dominicana & 1996 & 12 & 9 & 1 & 0 \\
\hline Equador & 1969 & 27 & 14 & 24 & 23 \\
\hline El Salvador & 1992 & 19 & 14 & 2 & 3 \\
\hline Granada & 1988 & 2 & 2 & 0 & 0 \\
\hline Guatemala & 2001 & 18 & 16 & 1 & 5 \\
\hline Haiti & 1975 & 3 & 3 & 0 & 0 \\
\hline Honduras & 1994 & 9 & 9 & 0 & 2 \\
\hline México & 1996 & 32 & 27 & 2 & 34 \\
\hline Nicarágua & 1995 & 14 & 12 & 1 & 2 \\
\hline Panamá & 1985 & 20 & 16 & 1 & 10 \\
\hline Paraguai & 1980 & 22 & 14 & 1 & 3 \\
\hline Peru & 1991 & 32 & 21 & 3 & 16 \\
\hline Uruguai & 1985 & 30 & 21 & 1 & 5 \\
\hline Venezuela & 1993 & 27 & 16 & 2 & 60 \\
\hline
\end{tabular}

Fonte: UNCTAD.

Elaboração do autor.

Os dados da tabela 2 mostram ainda que, nos últimos anos, determinados países não renovaram alguns de seus TBIs, notadamente a Bolívia e o Equador - este encerrou 24 dos seus 27 TBIs ratificados.

Esse fenômeno não ocorreu apenas na América Latina. A Índia, por exemplo, encerrou mais de setenta dos seus acordos de investimento nos últimos anos. Segundo UNCTAD (2018), em 2017 o número de acordos encerrados superou o número de acordos ratificados pela primeira vez. Um dos motivos para o encerramento de TBIs é o crescente número de reclamaçôes de investidores em tribunais internacionais. De acordo com dados da UNCTAD, ${ }^{12}$ dos países da América Latina elencados na tabela 2, apenas seis não receberam alguma reclamação formal. Das 257 reclamaçóes recebidas por países da América Latina, em 19,5\% a decisão foi dada a favor do Estado e em 25,6\% a favor da

11. Cabe salientar que o Brasil possui um modelo de acordo de investimentos diferente, chamado de Acordo de Cooperação e Facilitação de Investimentos (ACFI), já assinado com diversos países, mas ratificado apenas com Angola e México.

12. Dados disponíveis em: <https://investmentpolicy.unctad.org/investment-dispute-settlement>. 
empresa reclamante. ${ }^{13} \mathrm{~A}$ Argentina foi o país da região que mais enfrentou litígios, principalmente entre 2001 e 2005, época de elevada instabilidade macroeconômica do país. Ao mesmo tempo em que encerrou quase todos os seus acordos de investimento, o Equador também teve que responder a um número considerável de reclamaçóes e, em sete, o tribunal decidiu a favor do investidor, condenando o país a pagar elevados valores aos reclamantes.

\subsection{IED greenfield na América Latina}

Os dados do FDIMarkets mostram que empresas de 96 países realizaram investimentos do tipo greenfield na América Latina entre 2003 e 2019. Segundo mostra a figura 1, que representa os estoques de IED segundo o país de origem, empresas situadas nos Estados Unidos são as maiores investidoras na regiáo, seguido das empresas da Espanha e do Canadá. Aparentemente, os montantes de IEDs originados desses países são explicados pelas variáveis gravitacionais - ou que naturalmente tornam mais provável a existência de fluxos de investimento entre os países, tais como proximidade e o tamanho dessas economias -, além do idioma comum e do histórico colonial, no caso da Espanha. Nota-se também que entre os países da América Latina, o Brasil é o que mais investe na região. No continente asiático, China e Japão são os maiores parceiros nas relações de investimento com a América Latina.

\section{FIGURA 1}

\section{América Latina: origem do estoque de IED entre 2003 e 2018}
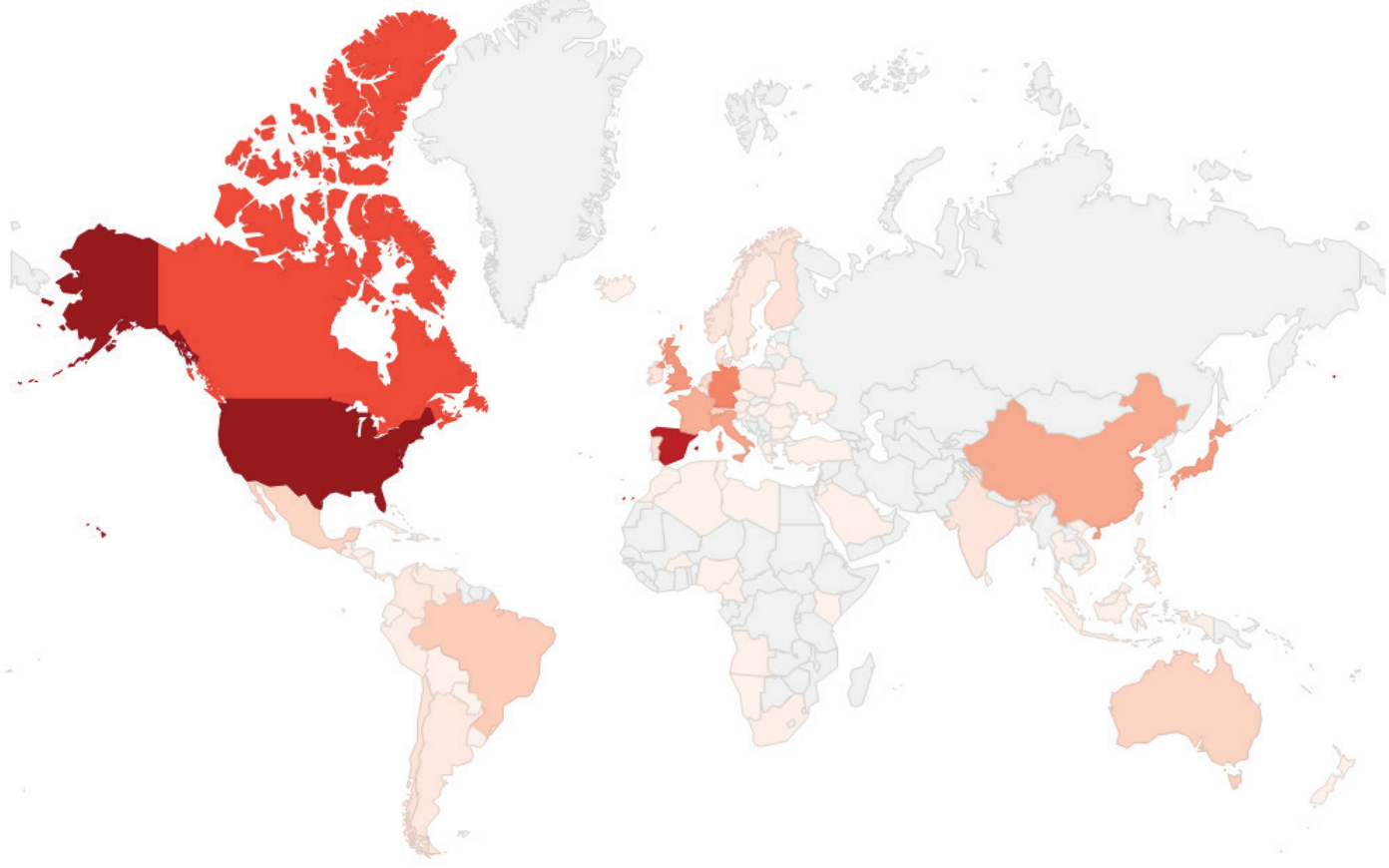

0,075 175.000

Fonte: FDIMarkets.

Elaboração do autor

13. Mais detalhes sobre os outros possíveis resultados para o julgamento no tribunal internacional estão disponíveis em: <https://investmentpolicy. unctad.org/investment-dispute-settlement>. 
Os países que mais acumularam IED na região no período analisado foram Brasil e México, concentrando cerca de 52\% do estoque de IED na América Latina (gráfico 2). Esses dois países em conjunto com Chile, Peru, Argentina e Colômbia detêm mais de $80 \%$ de todo o estoque de IED na América Latina. Os mesmos países concentram cerca de $73 \%$ do PIB da América Latina. Portanto, ao mesmo tempo que grandes economias são grandes emissoras de IED para a regiáo, as maiores economias latino-americanas são as que mais recebem esse tipo de investimento, indicando a existência de uma correlação entre os tamanhos das economias e os fluxos (saída e entrada) de IED.

\section{GRÁFICO 2}

\section{América Latina: destino do IED entre 2003 e 2019}

\section{(Em \%)}

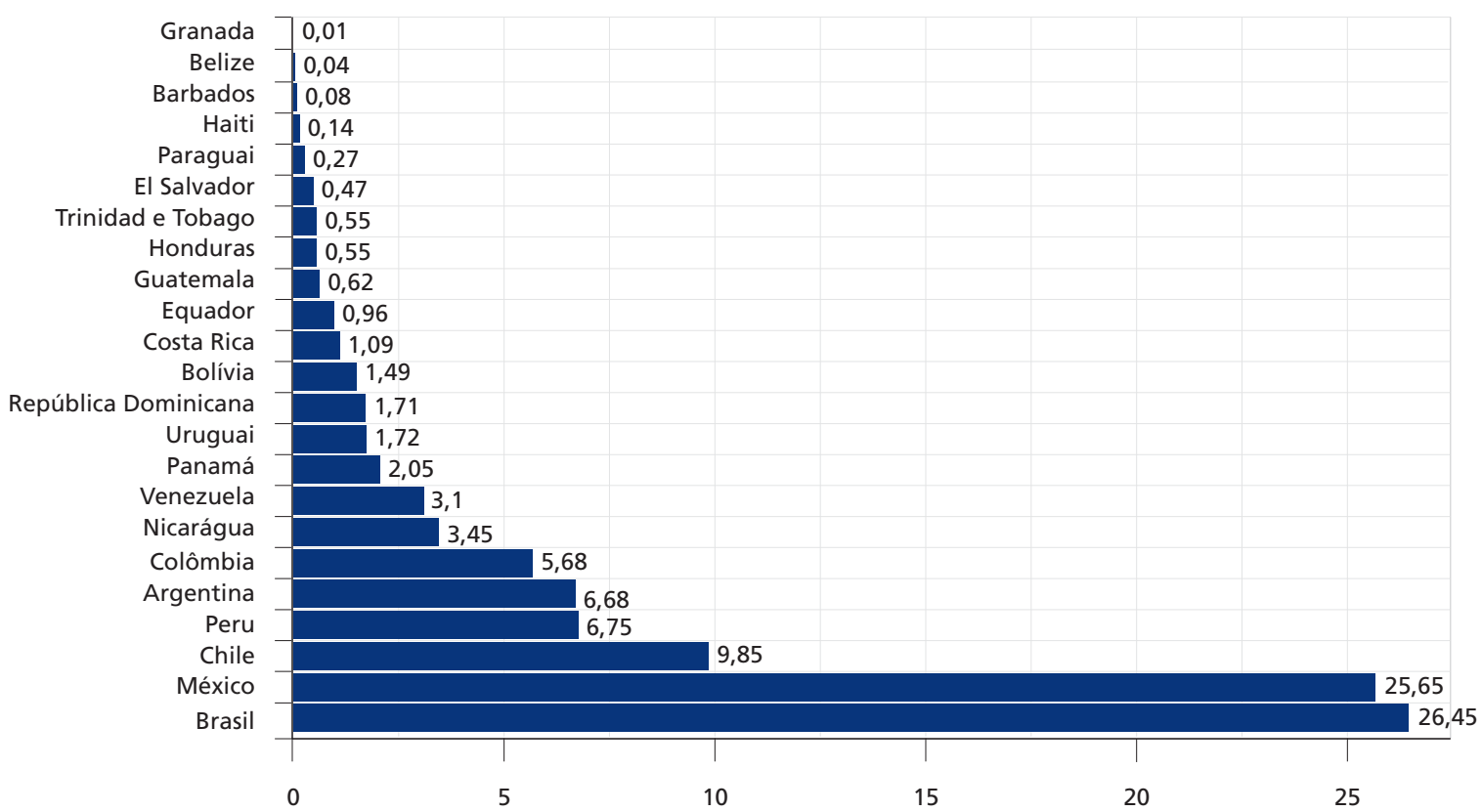

Fonte: FDIMarkets

Elaboração do autor.

Desagregado o IED na regiáo por setor de atividade econômica, obtém-se o gráfico 3. A classificação setorial adotada é a utilizada pelo FDIMarkets. As empresas do setor de metalurgia e siderurgia respondem por $16,12 \%$ de todo o IED realizado na América Latina no período em questáo, seguido dos investimentos na extração de carvão, óleo e gás, comunicaçôes, energias renováveis e no setor automotivo. Essas cinco atividades concentram 61,4\% do IED realizado na América Latina. Investimentos relacionados à extração de recursos naturais (metalurgia e siderurgia, carvão, óleo e gás e minerais) representam quase $30 \%$ de todo o IED realizado na regiáo. $\mathrm{Na}$ atividade de serviços, o setor de serviços financeiros é o que tem maior destaque, representado $4,77 \%$ do total de IED destinado à América Latina. 


\section{GRÁFICO 3}

\section{América Latina: distribuição do IED por setor de atividade econômica} (Em \%)

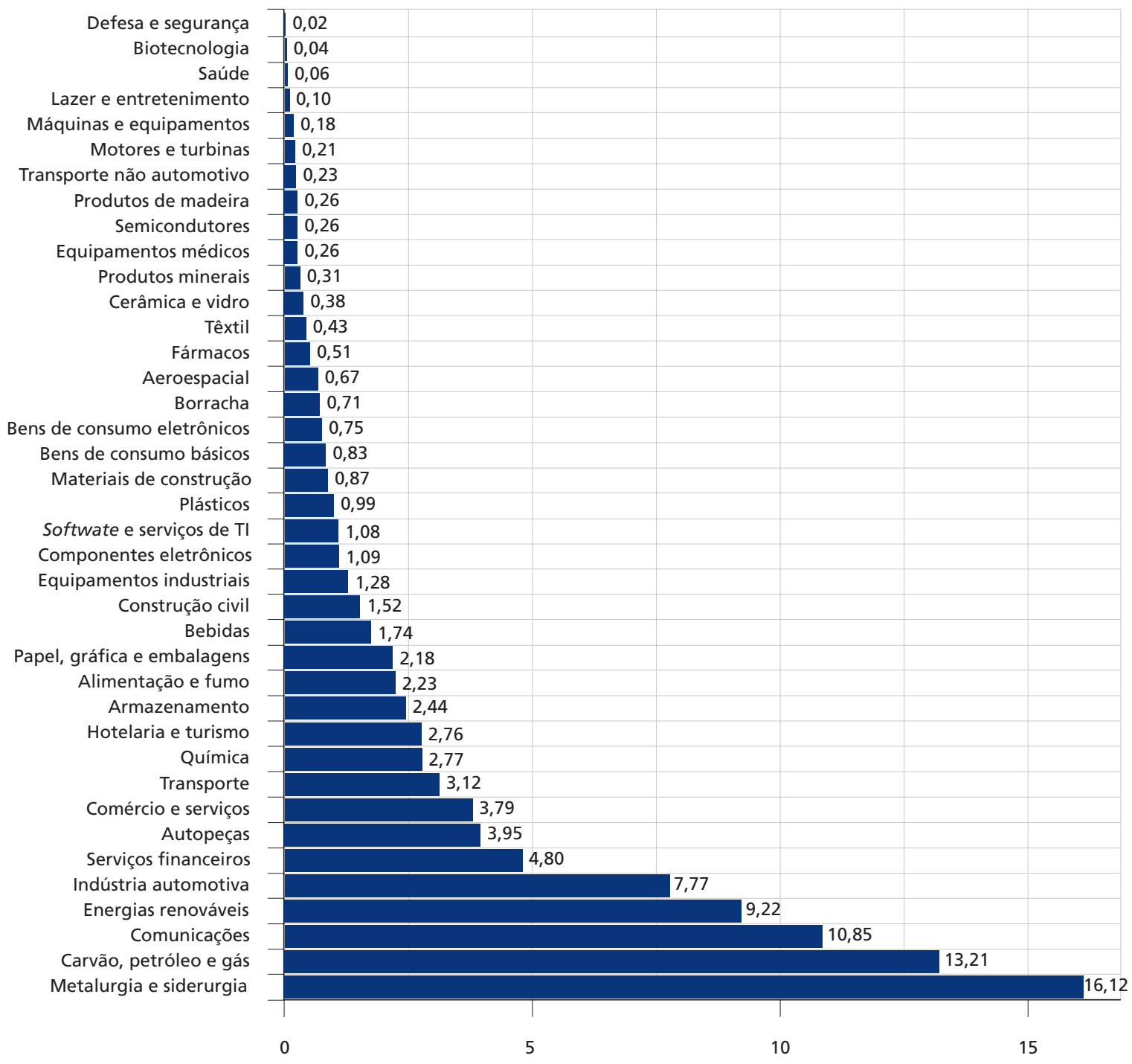

Fonte: FDIMarkets.

Elaboração do autor.

A figura 2 é um diagrama de Sankey ilustrando o fluxo de saída de IED por grupo de países para os setores e, em seguida, para os principais destinos de IED na América Latina. Para facilitar a visualização dos resultados, os setores foram agregados em três grupos, e os países de origem foram agregados conforme o continente a que pertencem. Apenas os principais destinos de IED foram exibidos na imagem.

A origem dos investimentos em setores industriais é dividida entre Europa, América do Norte e Leste Asiático. Os principais destinos dos investimentos de empresas desse segmento são Brasil e México, e a maior parcela de IED que chega nesses países é para o setor industrial, assim como na Argentina.

No setor de recursos naturais, os países europeus têm destaque próximo a Canadá e Estados Unidos em conjunto. Os principais destinos desses investimentos são Brasil, México, Chile e Peru. No Chile, Peru, Colômbia e Venezuela os investimentos são os mais relevantes na composição setorial do IED. 
FIGURA 2

Origem do estoque de IED dos principais países

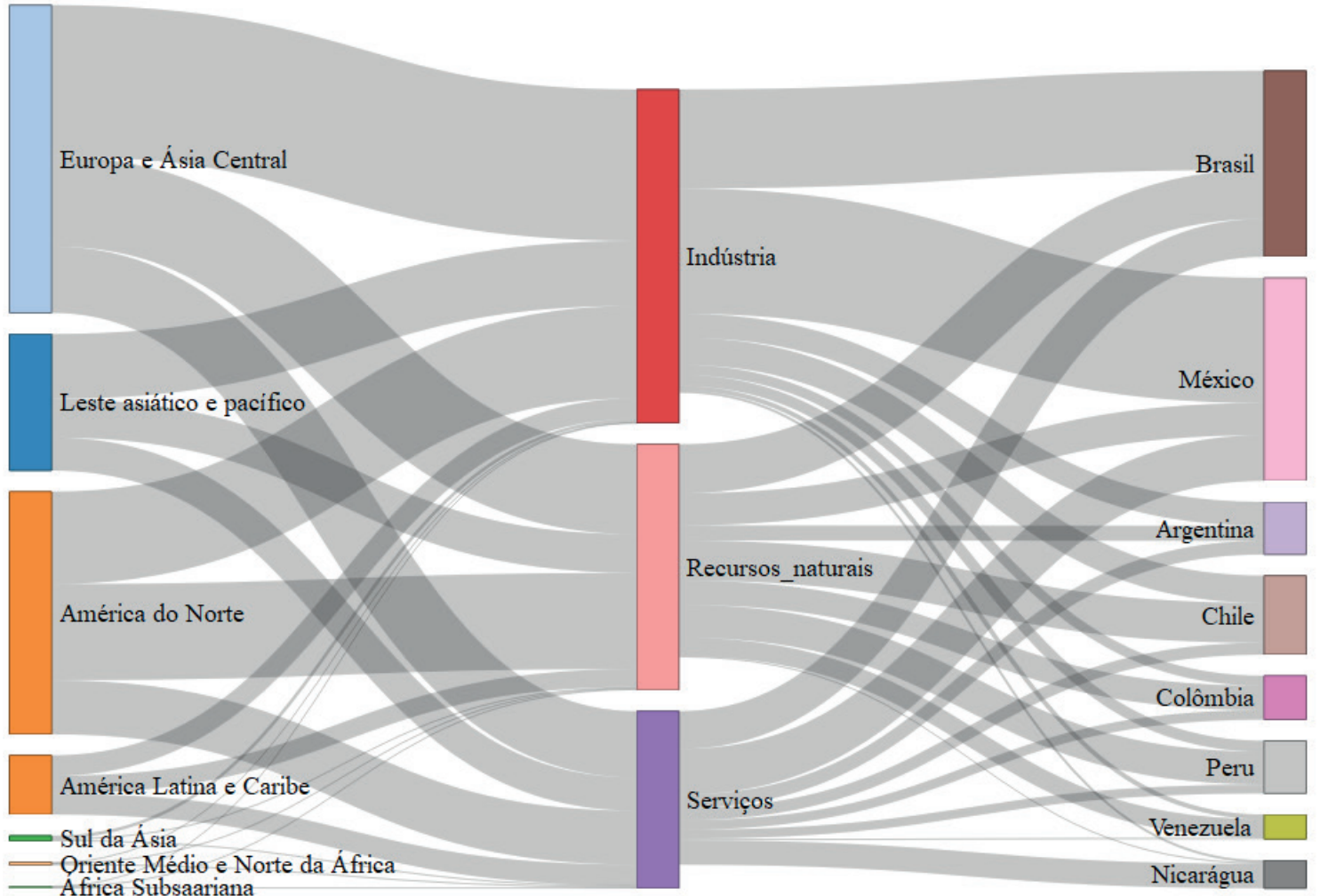

Fonte: FDIMarkets.

Elaboração do autor.

Obs.: Figura cujos leiaute e textos não puderam ser padronizados e revisados em virtude das condições técnicas dos originais (nota do Editorial).

Os investimentos no setor de serviços são originados principalmente de Europa, América do Norte e países do Leste Asiático. Os principais destinos são Brasil e México. Nota-se também que o IED na Nicarágua se origina quase que totalmente do setor de serviços. Os países da América Latina em conjunto investem menos do que os países do Leste Asiático (China e Japão inclusos). Percebe-se ainda que o IED originado na regiáo se distribui em parcelas semelhantes para os três agrupamentos de setores.

\section{EVIDÊNCIAS ECONOMÉTRICAS}

\subsection{Resultados gerais}

A tabela 3 reporta os resultados da estimação para seis versóes da equação (1), conforme a quantidade de variáveis consideradas. Inicialmente, o teste de erro de especificação de equaçáo de regressão (Regression Equation Specification Error Test - RESET) aponta que apenas os modelos 4, 5 e 6 apresentam uma especificação apropriada a $10 \%$ de significância.

A respeito dos resultados, nota-se que o parâmetro estimado para a variável dummy TBI não é estatisticamente significativo em nenhuma das especificaçóes da equaçáo (1), considerando efeitos 
fixos dos países, dos pares e de tempo. Já o efeito do crescimento real do PIB do país de destino é estatisticamente significativo a $1 \%$ em todos os modelos, indicando que a importância dessa variável para o ingresso de novos projetos de investimento nos países da região.

\section{TABELA 3}

Resultados da estimação do modelo gravitacional para IED

\begin{tabular}{|c|c|c|c|c|c|c|}
\hline \multirow{2}{*}{ Variáveis } & \multicolumn{6}{|c|}{ Modelos } \\
\hline & Modelo 1 & Modelo 2 & Modelo 3 & Modelo 4 & Modelo 5 & Modelo 6 \\
\hline$P I B_{i} \times P I B_{j}$ & $\begin{array}{c}0.0597 \\
(0.0432)\end{array}$ & $\begin{array}{c}0.0314 \\
(0.0466)\end{array}$ & $\begin{array}{c}0.0581 \\
(0.0551)\end{array}$ & $\begin{array}{l}0.0738 \\
(0.054)\end{array}$ & $\begin{array}{c}0.0735 \\
(0.0536)\end{array}$ & $\begin{array}{l}0.0934^{*} \\
(0.0556)\end{array}$ \\
\hline Taxa de crescimento do $P I B_{j}$ & $\begin{array}{c}0.0910 * * * \\
(0.0288)\end{array}$ & $\begin{array}{c}0.0911^{* * *} \\
(0.0271)\end{array}$ & $\begin{array}{c}0.0957^{* * *} \\
(0.0269)\end{array}$ & $\begin{array}{c}0.0961^{* * *} \\
(0.0262)\end{array}$ & $\begin{array}{c}0.0950^{* * *} \\
(0.0265)\end{array}$ & $\begin{array}{c}0.0738^{* * *} \\
(0.0272)\end{array}$ \\
\hline TBI (dummy) & $\begin{array}{l}-0.1027 \\
(0.2109)\end{array}$ & $\begin{array}{c}-0.1042 \\
(0.2134)\end{array}$ & $\begin{array}{l}-0.1307 \\
(0.2046)\end{array}$ & $\begin{array}{l}-0.1475 \\
(0.1824)\end{array}$ & $\begin{array}{l}-0.1571 \\
(0.1854)\end{array}$ & $\begin{array}{l}-0.2576 \\
(0.1898)\end{array}$ \\
\hline Grau de abertura comercial & & $\begin{array}{c}0.1948^{* *} \\
(0.0799)\end{array}$ & $\begin{array}{c}0.2926^{* * *} \\
(0.0898)\end{array}$ & $\begin{array}{c}0.2513^{* * *} \\
(0.0828)\end{array}$ & $\begin{array}{c}0.2296^{* * *} \\
(0.084)\end{array}$ & $\begin{array}{c}0.3170^{* * *} \\
(0.1028)\end{array}$ \\
\hline Taxa de Câmbio & & & $(0.0018)$ & $\begin{array}{c}0.0042 \\
(0.0029)\end{array}$ & $\begin{array}{c}0.0041 \\
(0.0029)\end{array}$ & $\begin{array}{l}-0.0054 \\
(0.0062)\end{array}$ \\
\hline Similaridade econômica & & & $\begin{array}{c}-0.0543 \\
(0.0343)\end{array}$ & $\begin{array}{c}-0.035 \\
(0.0309)\end{array}$ & $\begin{array}{l}-0.0311 \\
(0.031)\end{array}$ & $\begin{array}{c}-0.0283 \\
(0.0566)\end{array}$ \\
\hline Dissimilaridade de capital humano & & & $\begin{array}{c}0.2811 \\
(0.1737)\end{array}$ & $\begin{array}{l}0.2806^{*} \\
(0.1695)\end{array}$ & $\begin{array}{l}0.2796 \\
(0.171)\end{array}$ & $\begin{array}{c}0.0553 \\
(0.1575)\end{array}$ \\
\hline Dissimilaridade de dotação de fatores & & & $\begin{array}{l}-0.0052 \\
(0.0641)\end{array}$ & $\begin{array}{l}-0.0154 \\
(0.0604)\end{array}$ & $\begin{array}{l}-0.0138 \\
(0.0615)\end{array}$ & $\begin{array}{c}0.0531 \\
(0.0946)\end{array}$ \\
\hline Dissimilaridade de TIR & & & $\begin{array}{c}-0.3635^{* * *} \\
(0.1332)\end{array}$ & $\begin{array}{c}-0.3705^{* * *} \\
(0.1333)\end{array}$ & $\begin{array}{c}-0.3842^{* * *} \\
(0.1332)\end{array}$ & $\begin{array}{c}-0.5215^{* * *} \\
(0.184)\end{array}$ \\
\hline Recursos naturais & & & $\begin{array}{l}-0.0169 \\
(0.052)\end{array}$ & $\begin{array}{l}-0.0098 \\
(0.0499)\end{array}$ & $\begin{array}{l}-0.0073 \\
(0.0489)\end{array}$ & $\begin{array}{c}0.0069 \\
(0.07)\end{array}$ \\
\hline Respondeu por reclamação em tribunal internacional & & & & $\begin{array}{c}-0.3098^{* * *} \\
(0.1057)\end{array}$ & & \\
\hline Uma reclamação (dummy) & & & & & $\begin{array}{c}-0.3065^{* * *} \\
(0.1095)\end{array}$ & $\begin{array}{c}-0.3313^{* * *} \\
(0.0998)\end{array}$ \\
\hline Duas reclamações (dummy) & & & & & $\begin{array}{c}-0.3012^{* * *} \\
(0.0981)\end{array}$ & $\begin{array}{c}-0.2961^{* * *} \\
(0.0817)\end{array}$ \\
\hline Três reclamações (dummy) & & & & & $\begin{array}{c}-0.4739 * * * \\
(0.1666)\end{array}$ & $\begin{array}{c}-0.4958^{* * *} \\
(0.1469)\end{array}$ \\
\hline Quatro reclamações (dummy) & & & & & $\begin{array}{c}-0.3258^{* *} \\
(0.1343)\end{array}$ & $\begin{array}{c}-0.3159^{* *} \\
(0.1266)\end{array}$ \\
\hline Cinco reclamações (dummy) & & & & & $\begin{array}{c}-0.2875^{* *} \\
(0.13)\end{array}$ & $\begin{array}{c}-0.2790^{* *} \\
(0.1156)\end{array}$ \\
\hline Seis ou mais reclamações (dummy) & & & & & $\begin{array}{c}-0.5383^{* * *} \\
(0.1826)\end{array}$ & $\begin{array}{c}-0.5189^{* * *} \\
(0.1508)\end{array}$ \\
\hline Qualidade regulatória & & & & & & $\begin{array}{c}0.2372^{* *} \\
(0.1108)\end{array}$ \\
\hline Constante & $\begin{array}{c}7.1178^{* * *} \\
(1.2416)\end{array}$ & $\begin{array}{c}7.2123^{* * *} \\
(1.4226)\end{array}$ & $\begin{array}{c}6.2643^{* * *} \\
(1.7301)\end{array}$ & $\begin{array}{c}6.0933^{* * *} \\
(1.6984)\end{array}$ & $\begin{array}{c}6.2208^{* * *} \\
(1.6829)\end{array}$ & $\begin{array}{c}5.3929 * * * \\
(1.7499)\end{array}$ \\
\hline N & 9840 & 9840 & 8841 & 8841 & 8841 & 7333 \\
\hline Pseudo R2 & 0.967 & 0.9672 & 0.9681 & 0.9686 & 0.9688 & 0.9702 \\
\hline RESET (Prob > chi2) & 0.0016 & 0.0206 & 0.0508 & 0.4527 & 0.3711 & 0.9440 \\
\hline
\end{tabular}

Elaboração do autor.

Obs.: 1. Erro-padrão robusto entre parênteses.

2. Significância $\left({ }^{*}\right)=10 \% ;\left({ }^{* *}\right)=5 \% ;\left(^{* *}\right)=1 \%$.

O parâmetro associado ao grau de abertura comercial apresentou sinal positivo e é estatisticamente significativo a 1\% nos modelos mais completos. Conforme argumenta Helpman (1984), nesse caso, 
o grau de abertura comercial e o IED possivelmente estão relacionados em razão de projetos de integração vertical implementados na América Latina por empresas multinacionais. Ou seja, empresas estrangeiras fazem investimentos nos países latino-americanos na expectativa de complementar ou compor etapas de suas cadeias de produção, e, com isso, países em que é mais fácil realizar trocas comerciais seriam mais propensos a receber esses projetos.

A taxa bilateral de câmbio não possui efeito estatisticamente significativo sobre o IED. As variáveis que representam a similaridade entre os tamanhos das economias e as medidas de dissimilaridade de dotação de fatores de produção não aparentam influenciar o IED. Encontrou-se um resultado estatisticamente significativo a 5\% na medida de dissimilaridade de retorno do capital. Ou seja, em países em que as taxas internas de retorno são mais diferentes, os fluxos de IED são menores. Isso confirma a hipótese levantada de que empresas multinacionais buscam países em que o retorno do capital seja ao menos similar ao observado no seu país de origem.

Quando a taxa interna de retorno é um critério para avaliar um projeto diante do seu custo de capital, pode-se inferir, a partir desse resultado, que as empresas buscam opçóes de investimento em outros países com custo de capital similares ao de seus países. Apesar da região receber muitos projetos de investimento relacionados à extração de recursos naturais e produção de seus derivados, o parâmetro da variável que representa a dotaçáo de recursos naturais não foi estatisticamente significativo em nenhum dos modelos estimados.

A partir do modelo 4, observa-se significância estatística de 1\% para a estimativa do parâmetro da variável dummy indicando se o país recebeu alguma reclamação de um investidor de país parceiro no TBI. No modelo 5, foram incluídas variáveis dummy indicando quantas reclamaçóes o país recebeu. Em qualquer quantidade de reclamações, observam-se efeitos negativos. Esse efeito é consideravelmente maior no caso em que o país recebeu seis ou mais reclamaçóes. Portanto, de maneira geral, responder numa corte arbitral àlguma reclamação de uma empresa contestando alguma medida do governo que vai de encontro aos termos do TBI tem efeito negativo no IED, e esse efeito aumenta à medida que mais reclamaçôes são feitas, confirmando evidências similares em Allee e Peinhardt (2010) e Aisbett, Busse e Nunnenkamp (2018). Muito provavelmente, esse efeito negativo pode ser atribuído à perda de credibilidade que o país experimenta ao ser contestado em algum tribunal internacional.

Por fim, no modelo 6 é explorado o papel da qualidade regulatória nos fluxos de IED. Foi evidenciado que a variável de qualidade regulatória é positivamente relacionada com o IED. Esse resultado corrobora os estudos de Daude e Stein (2007) e sugere que países da América Latina recebem maiores volumes de IED quando leis e regulamentos são aplicados em favor do desenvolvimento empresarial.

\subsection{Resultados setoriais}

Os resultados da estimação da equação (1) considerando os efeitos fixos relacionados aos setores estão reportados na tabela 4. Nota-se que a inclusão de efeitos fixos setoriais não alterou substancialmente os resultados apresentados anteriormente. De acordo com os parâmetros estimados, a ratificação de acordos de investimento náo resultou em aumento no recebimento de mais investimento externo. O tamanho das economias que recebem e que originam o IED, porém, tem relevância na definição do ingresso de IED, e os países da América Latina que apresentam maiores taxas de crescimento tendem a receber mais investimento greenfield. Países com maiores correntes de comércio apresentam 
maiores ingressos de IED, provavelmente, como discutido anteriormente, direcionados para projetos de integração vertical.

As empresas também buscam países com taxas de retorno do capital semelhante ao observado em seus países de origem, conforme indica o resultado para a variável de dissimilaridade da taxa interna de retorno do capital. A qualidade regulatória tem efeito positivo e estatisticamente significativo sobre o IED, e o fato de o país de destino ter sofrido alguma reclamação num tribunal de arbitragem faz o IED ser menor do que para os países que náo foram denunciados por violar termos de acordo de investimento. $\mathrm{O}$ fato de o país ter recebido queixas de investidores tem efeito negativo sobre o IED, e esse efeito aumenta com o número de reclamaçóes. Quem recebe seis ou mais reclamaçóes tem importantes perdas de investimento externo.

As variáveis de interação entre as variáveis dummy de setor e de TBI não são estatisticamente significativas em nenhum dos agrupamentos considerados. Efeitos setoriais do TBI sobre IED seriam plausíveis na presença de custos irrecuperáveis intrínsecos de projetos em setores específicos e que demandariam a segurança jurídica de um acordo de investimento. A presença desses custos irrecuperáveis, no entanto, pode ser um efeito fixo setorial invariável no tempo, muitas vezes não observável corretamente, e que foi eliminado no processo de estimação do modelo. Acredita-se que, por esses argumentos, os investimentos nesses setores náo se tornam maiores quando o país tem um acordo de investimento ratificado.

TABELA 4

Resultados da estimação do modelo gravitacional para IED considerando efeitos fixos setoriais

\begin{tabular}{|c|c|c|c|c|}
\hline \multirow{2}{*}{ Variáveis } & \multicolumn{4}{|c|}{ Modelos } \\
\hline & Modelo 1 & Indústria & Serviços & Recursos naturais \\
\hline$P I B_{i} \times P I B_{j}$ & $\begin{array}{l}0.0947^{*} \\
(0.0539)\end{array}$ & $\begin{array}{l}0.0945^{*} \\
(0.0539)\end{array}$ & $\begin{array}{l}0.0945^{*} \\
(0.0539)\end{array}$ & $\begin{array}{l}0.0948^{*} \\
(0.0538)\end{array}$ \\
\hline Taxa de crescimento do PIBj & $\begin{array}{c}0.0747^{* * *} \\
(0.0278)\end{array}$ & $\begin{array}{c}0.0744^{* * *} \\
(0.0278)\end{array}$ & $\begin{array}{c}0.0748^{* * *} \\
(0.0278)\end{array}$ & $\begin{array}{c}0.0745^{* * *} \\
(0.0278)\end{array}$ \\
\hline TBI (dummy) & $\begin{array}{c}-0.2631 \\
(0.1859)\end{array}$ & $\begin{array}{l}-0.2795 \\
(0.1956)\end{array}$ & $\begin{array}{l}-0.2541 \\
(0.2019)\end{array}$ & $\begin{array}{l}-0.2392 \\
(0.1808)\end{array}$ \\
\hline Grau de abertura comercial & $\begin{array}{c}0.3190^{* * *} \\
(0.0985)\end{array}$ & $\begin{array}{c}0.3189^{* * *} \\
(0.0985)\end{array}$ & $\begin{array}{c}0.3200^{* * *} \\
(0.0991)\end{array}$ & $\begin{array}{c}0.3181^{* * *} \\
(0.0989)\end{array}$ \\
\hline Taxa de Câmbio & $\begin{array}{c}-0.006 \\
(0.0063)\end{array}$ & $\begin{array}{c}-0.006 \\
(0.0063)\end{array}$ & $\begin{array}{c}-0.006 \\
(0.0063)\end{array}$ & $\begin{array}{c}-0.006 \\
(0.0063)\end{array}$ \\
\hline Similaridade econômica & $\begin{array}{c}-0.0272 \\
(0.0573)\end{array}$ & $\begin{array}{l}-0.0268 \\
(0.0572)\end{array}$ & $\begin{array}{c}-0.0275 \\
(0.0573)\end{array}$ & $\begin{array}{l}-0.0267 \\
(0.0571)\end{array}$ \\
\hline Dissimilaridade de capital humano & $\begin{array}{c}0.0508 \\
(0.1497)\end{array}$ & $\begin{array}{c}0.0505 \\
(0.1495)\end{array}$ & $\begin{array}{c}0.0507 \\
(0.1497)\end{array}$ & $\begin{array}{c}0.0506 \\
(0.1496)\end{array}$ \\
\hline Dissimilaridade de dotação de fatores & $\begin{array}{c}0.0506 \\
(0.0948)\end{array}$ & $\begin{array}{c}0.0507 \\
(0.0947)\end{array}$ & $\begin{array}{c}0.0509 \\
(0.0948)\end{array}$ & $\begin{array}{c}0.0503 \\
(0.0947)\end{array}$ \\
\hline Dissimilaridade de TIR & $\begin{array}{c}-0.5225^{* * *} \\
(0.1876)\end{array}$ & $\begin{array}{c}-0.5221^{* * *} \\
(0.1876)\end{array}$ & $\begin{array}{c}-0.5233^{* * *} \\
(0.1876)\end{array}$ & $\begin{array}{c}-0.5216^{* * *} \\
(0.1876)\end{array}$ \\
\hline Qualidade regulatória & $\begin{array}{c}0.2415^{* *} \\
(0.1118)\end{array}$ & $\begin{array}{c}0.2424^{* *} \\
(0.1113)\end{array}$ & $\begin{array}{c}0.2408^{* *} \\
(0.1115)\end{array}$ & $\begin{array}{c}0.2426^{* *} \\
(0.1104)\end{array}$ \\
\hline Recursos naturais & $\begin{array}{c}0.006 \\
(0.0703)\end{array}$ & $\begin{array}{c}0.0063 \\
(0.0702)\end{array}$ & $\begin{array}{c}0.0057 \\
(0.0703)\end{array}$ & $\begin{array}{c}0.0064 \\
(0.0701)\end{array}$ \\
\hline Uma reclamação (dummy) & $\begin{array}{c}-0.3304^{* * *} \\
(0.0944)\end{array}$ & $\begin{array}{c}-0.3293^{* * *} \\
(0.0936)\end{array}$ & $\begin{array}{c}-0.3313^{* * *} \\
(0.0941)\end{array}$ & $\begin{array}{c}-0.3291^{* * *} \\
(0.0926)\end{array}$ \\
\hline Duas reclamações (dummy) & $\begin{array}{c}-0.2944^{* *} \\
(0.1193)\end{array}$ & $\begin{array}{c}-0.2943^{* *} \\
(0.1194)\end{array}$ & $\begin{array}{c}-0.2922^{* *} \\
(0.1197)\end{array}$ & $\begin{array}{c}-0.2964^{* *} \\
(0.1202)\end{array}$ \\
\hline
\end{tabular}




\begin{tabular}{|c|c|c|c|c|}
\hline \multirow{2}{*}{ Variáveis } & \multicolumn{4}{|c|}{ Modelos } \\
\hline & Modelo 1 & Indústria & Serviços & Recursos naturais \\
\hline Três reclamações (dummy) & $\begin{array}{c}-0.4943^{* * *} \\
(0.1582)\end{array}$ & $\begin{array}{c}-0.4952^{* * *} \\
(0.1583)\end{array}$ & $\begin{array}{c}-0.4909^{* * *} \\
(0.159)\end{array}$ & $\begin{array}{c}-0.4979^{* * *} \\
(0.1586)\end{array}$ \\
\hline Quatro reclamações (dummy) & $\begin{array}{l}-0.3106 \\
(0.1895)\end{array}$ & $\begin{array}{c}-0.3110^{*} \\
(0.1871)\end{array}$ & $\begin{array}{r}-0.3043 \\
(0.192)\end{array}$ & $\begin{array}{c}-0.3166^{*} \\
(0.1878)\end{array}$ \\
\hline Cinco reclamações (dummy) & $\begin{array}{l}-0.2741 \\
(0.1689)\end{array}$ & $\begin{array}{l}-0.2743 \\
(0.1672)\end{array}$ & $\begin{array}{l}-0.2688 \\
(0.1709)\end{array}$ & $\begin{array}{c}-0.2790^{*} \\
(0.1685)\end{array}$ \\
\hline Seis ou mais reclamações (dummy) & $\begin{array}{c}-0.5137^{* *} \\
(0.2025)\end{array}$ & $\begin{array}{c}-0.5140^{* *} \\
(0.2015)\end{array}$ & $\begin{array}{c}-0.5089^{* *} \\
(0.204)\end{array}$ & $\begin{array}{c}-0.5183^{* *} \\
(0.2031)\end{array}$ \\
\hline TBI x Indústria & & $\begin{array}{c}0.0838 \\
(0.2062)\end{array}$ & & \\
\hline TBI x Serviç̧os & & & $\begin{array}{c}-0.0432 \\
(0.1626)\end{array}$ & \\
\hline TBI x Recursos naturais & & & & $\begin{array}{c}-0.0401 \\
(0.23)\end{array}$ \\
\hline Constante & $3.6962^{* *}$ & $3.6987^{* *}$ & $3.6985^{* *}$ & $3.6953^{* *}$ \\
\hline N & 39969 & 39969 & 39969 & 39969 \\
\hline Pseudo R2 & 0.884 & 0.884 & 0.884 & 0.884 \\
\hline
\end{tabular}

Elaboração do autor.

Obs.:1. Erro-padrão robusto entre parênteses.

2. Significância $\left({ }^{*}\right)=10 \% ;\left({ }^{* *}\right)=5 \% ;\left({ }^{* *}\right)=1 \%$.

\section{CONSIDERAÇÕES FINAIS}

Tendo em vista a maior segurança que os tratados bilaterais de investimento propiciam aos investidores externos, espera-se que esses acordos favoreçam os fluxos de investimento principalmente para os países em desenvolvimento. Para os países da América Latina, marcados por cenários institucionais bem mais instáveis do que nos países ricos, é igualmente esperado que os acordos de investimento firmados elevem o ingresso de IED.

Todavia, segundo este estudo, não ficou evidenciada uma relação entre o ingresso de investimentos greenfiled e a ratificaçáo de acordos de investimento. Em outras palavras, controlando para as variáveis consideradas no modelo estimado e diversos efeitos fixos, há países atraindo vultosos projetos de investimentos de empresas de outros países mesmo sem haver acordos de investimento entre os dois países, como é o caso da economia brasileira.

Com base no modelo gravitacional estimado, foram encontradas evidências de que o crescimento econômico dos países de destino é relevante para a atração do investimento, assim como o grau de abertura comercial. Observou-se, ainda, que as empresas multinacionais aparentam querer investir em países que apresentam taxa de retorno do capital semelhante à observada em seus países. Nesse sentido, os resultados encontrados reforçam o argumento em favor de melhorias institucionais nos países da América Latina.

Celebrar um TBI, entretanto, pode reduzir o ingresso de IED, caso o país de destino seja denunciado por algum investidor que se sentiu prejudicado diante de alguma conduta do governo do país de destino. Nessa hipótese, além de incorrer nos custos associados à sua defesa no tribunal internacional, o país ainda pode se tornar menos atrativo para novos projetos em razão da perda de credibilidade resultante da reclamação recebida. 
A análise setorial confirmou o importante papel desempenhado pelo crescimento econômico e pelo grau de abertura das economias para atrair investimentos para a regiáo. Mesmo considerando efeitos fixos setoriais, o efeito da qualidade regulatória foi positivo e estatisticamente significativo. No mesmo conjunto de estimaçóes, foram confirmados os efeitos negativos resultantes de receber reclamaçôes por violar os termos dos acordos de investimento.

Mesmo diante desses resultados, acredita-se que, ao reduzir os riscos do investimento, estabelecendo regras claras de indenização para o investidor no caso se expropriação e também por servir de canal de comunicação entre os governos dos países de origem e de destino na questáo dos investimentos externos, os acordos de investimento podem ser úteis.

Por fim, são desejáveis mudanças recentes nos formatos dos acordos de investimento, sendo mais bem definido o que deve ser considerado como expropriação indireta e também em relação aos termos que garantam o direito de regular e criar um bom ambiente de investimentos, sem perder o direito de criar regulaçóes que permitam perseguir objetivos de desenvolvimento sustentável e outros de natureza socioeconômica. Essas mudanças podem evitar muitas das reclamaçôes de investidores que geram perdas importantes no ingresso de IED em países em desenvolvimento como os da América Latina.

\section{REFERÊNCIAS}

AISBETT, E.; BUSSE, M.; NUNNENKAMP, P. Bilateral investment treaties as deterrents of host-country discretion: the impact of investor-state disputes on foreign direct investment in developing countries. Review of World Economics, v. 154, n. 1, p. 119-155, 2018.

ALLEE, Todd; PEINHARDT, Clint. Delegating differences: Bilateral investment treaties and bargaining over dispute resolution provisions. International Studies Quarterly, v. 54, n. 1, p. 1-26, 2010.

BAE, C.; KEUM, H. The impact of free trade agreements on foreign direct investment: the case of Korea. East Asian Economic Review, v. 17, n. 4, 2013. p. 417-444.

BARRELL, R.; PAIN, N. An econometric analysis of US foreign direct investment. The review of economics and statistics, v. 78, n. 2, p. 200-207, 1996.

BELLEMARE, M. F.; WICHMAN, C. J. Elasticities and the inverse hyperbolic sine transformation. Oxford Bulletin of Economics and Statistics. Oxford, United States: University of Oxford and John Wiley \& Sons Ltd, 2019.

BÉNASSY-QUÉRÉ, A.; COUPET, M.; MAYER, T. Institutional determinants of foreign direct investment. World economy, v. 30, n. 5, p. 764-782, 2007.

BERGER, A. et al. More stringent BITs, less ambiguous effects on FDI? Not a BIT! Economics Letters, v. 112, n. 3, p. 270-272, 2011.

BLONIGEN, B. Firm-specific assets and the link between exchange rates and foreign direct investment. American Economic Review, v. 87, n. 3, p. 447-65, 1997.

COLEN, L.; PERSYN, D.; GUARISO, A. Bilateral Investment Treaties and FDI: Does the Sector Matter? World Development, v. 83, p. 193-206, 2016.

DAUDE, C.; STEIN, E. The quality of institutions and foreign direct investment. Economics \& Politics, v. 19, n. 3, p. 317-344, 2007.

EGGER, P.; MERLO, V. BITs bite: An anatomy of the impact of bilateral investment treaties on multinational firms. The Scandinavian Journal of Economics, v. 114, n. 4, p. 1240-1266, 2012. 
EGGER, P.; PFAFFERMAYR, M. The proper panel econometric specification of the gravity equation: A three-way model with bilateral interaction effects. Empirical Economics, v. 28, n. 3, p. 571-580, 2003.

The impact of bilateral investment treaties on foreign direct investment. Journal of comparative economics, v. 32, n. 4, p. 788-804, 2004.

ELKINS, Z.; GUZMAN, A. T.; SIMMONS, B. A. Competing for capital: the diffusion of bilateral investment treaties, 1960-2000. International Organization, v. 60, n. 4, p. 811-846, 2006.

FAETH, I. Determinants of foreign direct investment - A tale of nine theoretical models. Journal of Economic Surveys, v. 23, n. 1, p.165-196, 2009.

FALVEY, R.; FOSTER-MCGREGOR, N. Heterogeneous effects of bilateral investment treaties. Review of World Economics, v. 153, n. 4, p. 631-656, 2017.

FRENKEL, M.; WALTER, B. Do bilateral investment treaties attract foreign direct investment? The role of international dispute settlement provisions. The World Economy, v. 42, n. 5, p. 1316-1342, 2019.

FOURNIER, J.-M. The negative effect of regulatory divergence on foreign direct investment, OECD Economics Department Working Papers, n. 1268. Paris: OECD Publishing, 2015.

GALLAGHER, K. P.; BIRCH, M. B. L. Do investment agreements attract investment? Evidence from Latin America. Journal of World Investment and Trade, v. 7, n. 6, p. 961-974, 2006.

GUZMAN, A. T. Explaining the popularity of bilateral investment treaties. In: SAUVANT, K. P.; SACHS, L. E. (Eds.) The effect of treaties in foreign direct investment: bilateral investment treaties, double taxation treaties, and investment flows. Oxford; New York: Oxford University Press, p. 73-98, 2009.

HALLWARD-DRIEMEIER, M. Do bilateral investment treaties attract foreign direct investment? Only a BIT... and they could bite. Washington, D. C.: World Bank Group, 2003. (Policy Research Working Paper Series, n. 3121).

HEAD, K.; RIES, J. C. FDI as an outcome of the market for corporate control: theory and evidence. Journal of International Economics, v. 74, n. 1, 2-20, 2008.

HELPMAN, E. A simple theory of international trade with multinational corporations. Journal of political economy, v. 92, n. 3, p. 451-471, 1984.

HELPMAN, E. Trade, FDI, and the Organization of Firms. Journal of economic literature, v. 44, n. 3, p. 589-630, 2006.

HELPMAN, E.; MELITZ, M. J.; YEAPLE, S. R. Export versus FDI with heterogeneous firms. American Economic Review, v. 94, n. 1, p. 300-316, 2004.

KERNER, A. Why should I believe you? the costs and consequences of bilateral investment treaties. International Studies Quarterly, v. 53, n. 1, p. 73-102, 2009.

KOHLER, W.; STÄHLER, F. The economics of investor protection: ISDS versus national treatment, Munich: CESifo, 2016. (CESifo Working Paper, n. 5766).

LEE, C.-Y.; JOHNSTON, N. P. Improving reputation BIT by BIT: bilateral investment treaties and foreign accountability. International Interactions, v. 42, n. 3, p. 429-451, 2016.

MISTURA, F.; ROULET, C. The determinants of foreign direct investment: Do statutory restrictions matter? 2019/01, Paris: OECD Publishing, 2019. (OECD Working Papers on International Investment, v. 2019 , n. 1).

NEUMAYER, E.; SPESS, L. Do bilateral investment treaties increase foreign direct investment to developing countries? World Development, v. 33, n. 10, p. 1567-1585, 2005. 
NICOLETTI, G. et al. The influence of policies on trade and foreign direct investment. OECD Economic Studies, v. 2003, n. 1, p. 7-83, 2003.

PEREA, J. R.; STEPHENSON, M. Outward FDI from developing countries. In: THE WORLD BANK GROUP. Global Investment Competitiveness Report 2017/2018. Washington, D. C.: World Bank, 2018, p. 101-134.

PRADHAN, J. P. Emerging multinationals: a comparison of chinese and indian outward foreign direct investment. International Journal of Institutions and Economies, v. 3, n. 1, p. 113-148, 2011.

RAMMAL, H. G.; ZURBRUEGG, R. The impact of regulatory quality on intra-foreign direct investment flows in the ASEAN markets. International Business Review, v. 15, n. 4, p. 401-414, 2006.

ROSE-ACKERMAN, S.; TOBIN, J. L. Foreign direct investment and the business environment in developing countries: the impact of bilateral investment treaties. Yale Law \& Economics Research Paper, n. 293, 2005.

SILVA, J. S.; TENREYRO, S. The Log of Gravity. The Review of Economics and Statistics, v. 88, n. 4, p. 641-658, 2006.

TOBIN, J. L.; ROSE-ACKERMAN, S. When BITs have some bite: the political-economic environment for bilateral investment treaties. Review of International Organizations, v. 6, n. 1, p. 1-32, 2011.

UNCTAD - United Nations Conference on Trade and Development. Bilateral Investment Treaties. Treaties 1959-1999. New York: United Nations Publication, 2000.

IIA Issues Note: Recent developments in the international investment regime. Geneva: UNCTAD, 2018. Disponível em: <https://unctad.org/system/files/official-document/diaepcbinf2018d1_en.pdf>.

YEAPLE, S. R. The role of skill endowments in the structure of US outward foreign direct investment. Review of Economics and Statistics, v. 85, n. 3, p. 726-734, 2003. 
ANEXO

QUADRO A. 1

Agrupamento de setores

\begin{tabular}{|c|c|}
\hline \multirow{25}{*}{ Indústria } & Aeroespacial \\
\hline & Autopeças \\
\hline & Indústria automotiva \\
\hline & Bebidas \\
\hline & Biotecnologia \\
\hline & Materiais de construção \\
\hline & Máquinas e equipamentos \\
\hline & Cerâmica e vidro \\
\hline & Química \\
\hline & Bens de consumo eletrônicos \\
\hline & Bens de consumo básicos \\
\hline & Componentes eletrônicos \\
\hline & Motores e turbinas \\
\hline & Alimentação e fumo \\
\hline & Equipamentos industriais \\
\hline & Equipamentos médicos \\
\hline & Transporte não automotivo \\
\hline & Papel, gráfica e embalagens \\
\hline & Fármacos \\
\hline & Plásticos \\
\hline & Energias renováveis \\
\hline & Borracha \\
\hline & Semicondutores \\
\hline & Têxtil \\
\hline & Produtos de madeira \\
\hline & Comércio e serviços \\
\hline & Comunicações \\
\hline & Serviços financeiros \\
\hline & Saúde \\
\hline & Hotelaria e turismo \\
\hline Serviços & Lazer e entretenimento \\
\hline & Software e serviços de TI \\
\hline & Defesa e segurança \\
\hline & Transporte \\
\hline & Armazenamento \\
\hline & Serviços imobiliários \\
\hline & Carvão, petróleo e gás \\
\hline Recursos naturais & Metalurgia e siderurgia \\
\hline & Produtos minerais \\
\hline
\end{tabular}

Fonte: FDIMarkets. 
QUADRO A.2

América Latina: países que realizaram investimentos greenfield na região entre 2003 e 2019

\begin{tabular}{|c|c|c|c|c|}
\hline Argélia & Ilhas Cayman & Hong Kong & Mônaco & Eslovênia \\
\hline Andorra & Chile & Hungria & Marrocos & África do Sul \\
\hline Angola & China & Islândia & Namíbia & Espanha \\
\hline Antígua e Barbuda & Colômbia & Índia & Países Baixos & Sri Lanka \\
\hline Argentina & Costa Rica & Indonésia & Nova Zelândia & Suécia \\
\hline Aruba & Cuba & Iran & Nicarágua & Suíça \\
\hline Austrália & Chipre & Irlanda & Noruega & Síria \\
\hline Áustria & República Checa & Israel & Panamá & Tailândia \\
\hline Bahamas & Dinamarca & Itália & Paraguai & Trinidad e Tobago \\
\hline Bangladesh & República Dominicana & Jamaica & Peru & Tunísia \\
\hline Barbados & Equador & Japão & Filipinas & Turquia \\
\hline Bielorrússia & El Salvador & Quênia & Polônia & Ucrânia \\
\hline Bélgica & Finlândia & Coreia do Sul & Portugal & Reino Unido \\
\hline Bermudas & França & Kuwait & Catar & Estados Unidos \\
\hline Bolívia & Alemanha & Letônia & Romênia & Uruguai \\
\hline Brasil & Grécia & Líbano & Federação Russa & Venezuela \\
\hline Bulgária & Guatemala & Liechtenstein & Arábia Saudita & Vietnã \\
\hline Camarões & Haiti & Malta & Singapura & Cisjordânia \\
\hline Canadá & Honduras & México & República Eslovaca & \\
\hline
\end{tabular}

Fonte: FDIMarkets. 